\title{
The NIST Plan for Providing Public Access to Results of Federally Funded Research
}

Katherine E. Sharpless

Regina L. Avila

Sally S. Bruce

Wo L. Chang

Virginia Covahey

Robert M. Dimeo

A. Kirk Dohne

Heather M. Evans

Aaron P. Fein

Donna J. Kimball

Andrea M. Medina-Smith

Alan E. Munter

James K. Olthoff

Dianne L. Poster

Kathleen M. Roberts

Susannah B. Schiller

John Henry J. Scott

Barbara P. Silcox

James A. St. Pierre

Mark D. Stiles

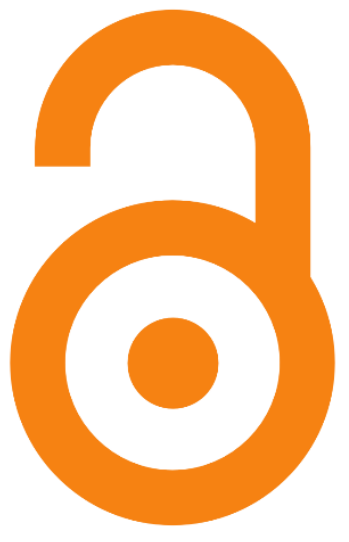

This publication is available free of charge from:

http://dx.doi.org/10.6028/NIST.IR.8084

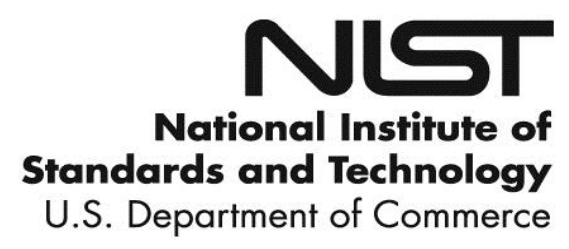


This publication is available free of charge from http://dx.doi.org/10.6028/NIST.IR.8084 


\title{
The NIST Plan for Providing Public Access to Results of Federally Funded Research
}

\author{
Katherine E. Sharpless, Special Programs Office \\ Regina L. Avila, Information Services Office \\ Sally S. Bruce, Standards Coordination Office \\ Wo L. Chang, Information Technology Laboratory \\ Virginia Covahey, Public Affairs Office \\ Robert M. Dimeo, NIST Center for Neutron Research \\ A. Kirk Dohne, Engineering Laboratory \\ Heather Evans, Program Coordination Office \\ Aaron P. Fein, Physical Measurement Laboratory \\ Donna J. Kimball, Laboratory Programs \\ Andrea M. Medina-Smith, Information Services Office \\ Alan E. Munter, NIST Center for Neutron Research \\ James K. Olthoff, Physical Measurement Laboratory \\ Dianne L. Poster, Laboratory Programs \\ Kathleen M. Roberts, Information Technology Laboratory \\ Susannah B. Schiller, Office of Information Systems Management \\ John Henry J. Scott, Material Measurement Laboratory \\ Barbara P. Silcox, Information Services Office \\ James A. St. Pierre, Information Technology Laboratory \\ Mark D. Stiles, Center for Nanoscale Science and Technology
}

This publication is available free of charge from http://dx.doi.org/10.6028/NIST.IR.8084

September 2015

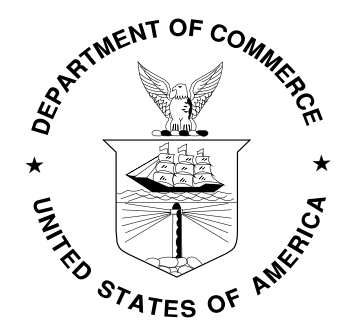

U.S. Department of Commerce Penny Pritzker, Secretary

National Institute of Standards and Technology Willie May, Under Secretary of Commerce for Standards and Technology and Director 
This publication is available free of charge from http://dx.doi.org/10.6028/NIST.IR.8084 


\section{Table of Contents}

Preface

National Institute of Standards and Technology Plan for Providing Public Access to the Results of Federally Funded Research ............................................................................. 2

Appendix A. Members of the committees responsible for drafting NIST's plan for providing public access to results of federally funded research................................................. 18

Appendix B. Feedback received from NIST staff's review of draft Public Access Plan and responses provided by the Data Policy Group. ............................................................... 19

Appendix C. Public feedback received in response to the Federal Register Notice of July 7 ,

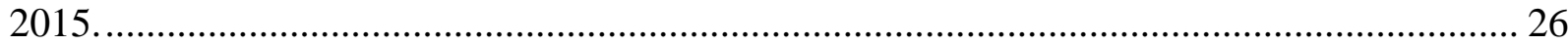

Appendix D. NIST Data Taxonomy and Actions/Consequences for Data Categories ............ 61 



\section{Preface}

In February 2013 the White House Office of Science and Technology Policy (OSTP) issued a memorandum requiring federal agencies to develop a plan for "Increasing Access to the Results of Federally Funded Scientific Research." 1 A draft plan for providing public access was developed by the Data Policy Group and Publications Working Group (Appendix A). The draft was posted for NIST staff review and comment in the summer of 2014. A summary of staff feedback and responses prepared by the Data Policy Group and the Publications Working Group is provided in Appendix B.

The NIST Plan for Providing Public Access to the Results of Federally Funded Research was approved by OSTP in December 2014. The plan is provided in the body of this report. The plan was posted for public comment, announced in a Federal Register Notice ${ }^{2}$ on July 7, 2015. All public feedback received is provided in Appendix C. This feedback will inform changes to the NIST directives for managing public access to the results of federally funded research, available at www.nist.gov/data.

The Data Policy Group also developed a data taxonomy for categorizing NIST data. The taxonomy is included in NIST O 5701.00 Managing Public Access to Results of Federally Funded Research. It is provided in Appendix D of this NISTIR to provide context for some of the points raised by NIST staff (Appendix B).

This report serves as the historical record of documents as originally approved.

\footnotetext{
${ }^{1}$ https://www.whitehouse.gov/sites/default/files/microsites/ostp/ostp_public_access_memo_2013.pdf

${ }^{2}$ http://www.gpo.gov/fdsys/pkg/FR-2015-07-07/pdf/2015-16508.pdf
} 


\section{National Institute of Standards and Technology \\ Plan for Providing Public Access to the \\ Results of Federally Funded Research}

\section{PURPOSE}

This document establishes a plan to enable public access to the results of research funded wholly or in part by NIST; NIST's Public Access Policy will be informed by this Public Access Plan. To the extent feasible and consistent with law, agency mission, resource constraints, U.S. national, homeland, and economic security, and the objectives listed below, NIST intends to make freely available to the public, in publicly accessible repositories, all peer-reviewed scholarly publications and associated data arising from unclassified research and programs funded wholly or in part by NIST. Subject to the same conditions and constraints listed above, NIST will also promote the deposit of scientific data arising from unclassified research and programs, funded wholly or in part by NIST, to make it available free of charge unless otherwise excepted, in publicly accessible databases. NIST's Public Access Plan promotes the following objectives:

- Establish NIST's commitment to providing public access to scientific research results

- Support governance of and best practices for managing peer-reviewed scholarly publications and digital scientific data across NIST

- Ensure effective access to and reliable preservation of NIST peer-reviewed scholarly publications and digital scientific data for use in research, development, education, and scientific discovery

- Enhance innovation and competitiveness by maximizing the potential to create new business opportunities.

\section{SCOPE}

The NIST Public Access Plan applies to the results of research funded wholly or in part by NIST, presented in peer-reviewed scholarly publications and as research data, defined in Circular A110 of the Office of Management and Budget as the "recorded factual material commonly accepted in the scientific community as necessary to validate research findings."

Not considered research data in Circular A-110, and therefore not covered by this plan, are:

- Laboratory notebooks, results of preliminary analyses, drafts of scientific papers, plans for future research, peer review reports, communications with colleagues, or physical objects, such as laboratory specimens;

- Trade secrets, commercial information, or other materials necessary to be held confidential by a researcher until they are published, or similar information that is protected under law; and

- Personnel and medical information and similar information the disclosure of which would constitute a clearly unwarranted invasion of personal privacy. 
NIST will protect confidentiality and personal privacy and will recognize proprietary interests, business confidential information, and intellectual property rights, avoiding significant negative impact on intellectual property rights, innovation, and U.S. competitiveness.

Implementation will be prospective and will not apply to NIST peer-reviewed scholarly publications published and research data created before NIST's Public Access Policy takes effect. However, NIST will endeavor to make legacy information publicly available and ensure its preservation as soon as practicable. A process will be created to engage with customers to help facilitate and prioritize information release.

\section{APPLICABILITY}

The NIST Public Access Plan applies to the following groups:

- All NIST employees who publish peer-reviewed scholarly material and data as part of their employment, including full- and part-time employees, temporary government employees, and special government employees;

- Awardees from non-NIST organizations that publish peer-reviewed scholarly material and data through activities funded wholly or in part by NIST through a grant, cooperative agreement, contract, or other agreement. This includes but is not limited to states, localities, regulated parties, non-profit and volunteer organizations, contractors, cooperative agreement holders, grantees, cooperating Federal agencies, intergovernmental organizations, universities, and other educational institutions. For activities funded by multiple sources with differing public access requirements, the provisions of this plan will apply unless otherwise specified by NIST in its funding documents.

\section{REQUIREMENTS}

To the extent feasible and consistent with law, agency mission, resource constraints, U.S. national, homeland, and economic security, and the objectives listed below, NIST intends to make freely available to the public, in publicly accessible repositories, all peer-reviewed scholarly publications and associated data arising from unclassified research and programs funded wholly or in part by NIST. Subject to the same conditions and constraints listed above, NIST will also promote the deposit of scientific data arising from unclassified research and programs, funded wholly or in part by NIST, free of charge unless otherwise excepted, in publicly accessible databases.

All proposals or plans for activities that will generate scientific data using NIST funding will be required to (1) adhere to a Data Management Plan (DMP) that describes how scientific data generated through the course of the proposed work will be shared and preserved or (2) explain why data sharing and/or preservation are not within the scope of this plan.

- Reasonable costs for data preservation and access may be included in grant proposals or project plan budgets for contracts. Grantee and contractor DMPs will be reviewed as part of the technical evaluation process.

- NIST managers will be required to ensure staff compliance with the requirements of DMPs, including those for preservation and discoverability. NIST managers will ensure that DMPs are considered in the context of employees' performance plans and evaluations. 
- Non-compliance with requirements by staff and funding recipients will result in penalties; policies will evolve over time.

Authors of peer-reviewed scholarly publications are required to submit to the NIST public access archive system metadata and their copies of final peer-reviewed journal manuscripts within the scope of this plan once the manuscript is accepted for publication. In lieu of the author's version of the final peer-reviewed manuscript, NIST will also accept the final published article, as formatted by the journal, provided the author has the right to submit the published version.

NIST's plan further requires that the final manuscript, which has been peer-reviewed and accepted for publication, be freely available to the public no later than 12 months following publication.

\section{AUTHORITY}

NIST's authority to require broad public access to the results of federally funded research stems from multiple sources, including, but not necessarily limited to, those below.

- Executive Office of the President, Memorandum for the Heads of Executive Departments and Agencies: Increasing Access to the Results of Federally Funded Scientific Research, dated February 22, 2013, requires that the direct results of federally funded scientific research, including that of awardees, be made available to and useful for the public, industry, and the scientific community. Available at http://www.whitehouse.gov/sites/default/files/microsites/ostp/ostp_public_access_memo 2013.pdf (Accessed 10 February 2014.)

- Memorandum for the Heads of Executive Departments and Agencies - Transparency and Open Government, Executive Office of the President, January 21, 2009, requires that be transparent, participatory, and collaborative. http://www.whitehouse.gov/the_press_office/TransparencyandOpenGovernment (Accessed 8 April 2014.)

- Open Government Directive (M10-06) issued on December 8, 2009 directs executive departments and agencies that, "to increase accountability, promote informed participation by the public, and create economic opportunity, each agency shall take prompt steps to expand access to information by making it available online in open formats." http://www.whitehouse.gov/open/documents/open-government-directive (Accessed 10 February 2014.)

- The Office of Management and Budget (OMB) Memorandum M-13-13 Open Data Policy - Managing Information as an Asset dated May 9, 2013, requires that agencies collect or create information in a way that supports downstream processing and dissemination (e.g., use of machine-readable and open formats and extensible metadata). http://www.whitehouse.gov/sites/default/files/omb/memoranda/2013/m-13-13.pdf (Accessed 8 April 2014.)

- The Office of Management and Budget (OMB) Circular A-110, Uniform Administrative Requirements for Grants and Agreements with Institutions of Higher Education, Hospitals, and Other Non-Profit Organizations (section 36) specifies "The Federal awarding agency(ies) reserve a royalty-free, nonexclusive and irrevocable right to reproduce, publish, or otherwise use the work for Federal purposes, and to authorize 
others to do so." http://www.whitehouse.gov/omb/circulars_a110/ (Accessed 10 February 2014.)

- The Office of Management and Budget (OMB) Circular A-130, Management of Federal Information Resources, states that "[ $\mathrm{t}] \mathrm{he}$ open and efficient exchange of scientific and technical government information ... fosters excellence in scientific research and effective use of federal research and development funds." http://www.whitehouse.gov/omb/circulars_a130_a130trans4/ (Accessed 10 February 2014.)

- The Freedom of Information Act (FOIA; 5 U.S.C. 552) provides for public access to the records of the federal government. http://www.gpo.gov/fdsys/pkg/USCODE-2011title5/html/USCODE-2011-title5-partI-chap5-subchapII-sec552.htm (Accessed 10 February 2014.)

- National Institute of Standards and Technology Act (15 U.S.C. 271, Chapter 7) states the responsibility of NIST to "compile, evaluate, publish, and otherwise disseminate general, specific, and technical data resulting from the performance of the functions specified in this section or from other sources when such data are important to science, engineering, or industry, or to the general public, and are not available elsewhere." http://www.gpo.gov/fdsys/pkg/USCODE-2011-title15/html/USCODE-2011-title15chap7-sec271.htm (Accessed 24 January 2014) and http://www.nist.gov/director/ocla/upload/NIST-Organic-Act.pdf (Accessed 10 April 2014)

- Copyright Act (17 U.S.C. 105, Section 105) provides that "copyright protection under this title is not available for any work of the United States Government." http://uscode.house.gov/view.xhtml?req=(title:17\%20section:105\%20edition:prelim (Accessed 24 January 2014)

- The E-Government Act of 2002 (44 U.S.C. 101) has among its primary purposes the promotion of "the use of the Internet and emerging technologies within and across Government agencies to provide citizen-centric Government information and services" as well as providing "enhanced access to Government information and services." http://www.gpo.gov/fdsys/pkg/PLAW-107publ347/pdf/PLAW-107publ347.pdf (Accessed 8 April 2014)

- Public Law 90-396 Standard Reference Data Act provides for publication and copyright of Standard Reference Data. http://www.nist.gov/srd/upload/publiclaw90-396.pdf (Accessed 24 January 2014)

- Public Law 104-13, The Paperwork Reduction Act of 1995 has as one of its key purposes to "ensure the greatest possible public benefit from and maximize the utility of information created, collected, maintained, used, shared, and disseminated by or for the federal government." http://www.reginfo.gov/public/reginfo/pra.pdf (Accessed 8 April 2014.)

- Public Law 111-358, Section 103, The America COMPETES Reauthorization Act of 2010 outlines the responsibility of a working group of the National Science and Technology Council "to coordinate Federal science agency research and policies related 
to the dissemination and long-term stewardship of the results of unclassified research, including digital data and peer-reviewed scholarly publications, supported wholly, or in part, by funding from the Federal science agencies." http://www.gpo.gov/fdsys/pkg/PLAW-111publ358/pdf/PLAW-111publ358.pdf (Accessed 10 February 2014.)

NIST's Public Access Plan and resulting policies do not rescind any other Department of Commerce or NIST policies or guidance and do not alter or supersede existing law or regulations, including NIST's fee recovery authority for the provision of calibrations and Standard Reference Materials (15 USC 275c) and Standard Reference Data (15 USC 271-278e), which is further articulated in Public Law 90-396, the Standard Reference Data Act.

\section{ROLES AND RESPONSIBILITIES}

\section{The NIST Director}

- Controls and manages NIST's Policy and Order on Managing Public Access to Results of Federally Funded Research.

- Ensures coordination of the management of public access to results of federally funded research with non-NIST organizations, as applicable.

\section{Associate Director for Laboratory Programs (ADLP)}

- Implements and provides oversight for maintenance of, and compliance with, NIST's Policy and Order on Managing Public Access to Results of Federally Funded Research.

- Ensures the availability of appropriate resources for managing public access to results of federally funded research.

- Reviews, approves, and evaluates the effectiveness of NIST OU and Office plans for managing public access to results of federally funded research.

- Ensures compliance with NIST's Policy and Order on Managing Public Access to Results of Federally Funded Research.

- Coordinates collaboration and cooperation on implementation of the NIST's Policy and Order on Managing Public Access to Results of Federally Funded Research across NIST and with the Department of Commerce and other federal agencies.

- With the Associate Director for Management Resources (ADMR) and the Associated Director for Innovation and Industry Services (ADIIS), coordinates with relevant OUs and Offices in their infrastructure planning and implementation to promote interoperability across NIST.

- With the ADMR and Chief Information Officer (CIO), coordinates with relevant OUs and Offices in their infrastructure planning and implementation to promote interoperability across NIST.

- With the ADMR and CIO, coordinates collaboration and cooperation on implementation of this plan across NIST, and with the Department of Commerce and other Federal agencies.

\section{Associate Director for Management Resources (ADMR)}

- Facilitates the provision of NIST-level infrastructure to manage public access to results of federally funded research. 
- Ensures the development and deployment of training, awareness, and outreach activities pertaining to the management of public access to results of federally funded research.

- With the ADLP and ADIIS, coordinates with relevant OUs and Offices in their infrastructure planning and implementation to promote interoperability across NIST.

- Oversees the activities of the Chief Information Officer and the Directors of the Information Services Office and Office of Acquisition and Agreements Management in supporting NIST's Policy and Order on Managing Public Access to Results of Federally Funded Research, as applicable.

- With the ADLP and CIO, coordinates collaboration and cooperation on implementation of this plan across NIST, and with the Department of Commerce and other Federal agencies.

\section{Associate Director for Innovation and Industry Services}

- Oversees the activities of the Directors of the Advanced Manufacturing National Program Office, the Baldrige Performance Excellence Program, the Economic Analysis Office, the Hollings Manufacturing Extension Partnership, the Technology Innovation Program, and the Technology Partnership Office in supporting NIST's Policy and Order on Managing Public Access to Results of Federally Funded Research, as applicable.

\section{NIST Chief Information Officer (CIO)}

- Manages NIST-level information technology infrastructure to support NIST's provision of public access to results of federally funded research.

- Ensures that the NIST Enterprise Data Inventory (EDI) is available to NIST employees and that NIST inventory records are provided to the Department of Commerce and government-wide inventories in the necessary format, per Office of Management and Budget requirements.

- Supports NIST OU and Office Directors' responsibilities (see Section VI.6. of this Order), as applicable.

- With the ADLP and ADMR, coordinates with relevant OUs and Offices in their infrastructure planning and implementation to promote interoperability across NIST.

- With the ADLP and ADMR, coordinates with other agency CIOs and with the Federal CIO Council to promote interoperability across agencies.

\section{Director, Information Services Office}

- Works with the Office of Information Systems Management (OISM) to ensure implementation and operation of the NIST EDI.

- Curates metadata for NIST scholarly publications and scientific research data for publicly available repositories.

- Manages creation and maintenance of persistent identifiers for NIST Technical Series Publications.

- Develops data citation methods to facilitate attribution to NIST scientific data sets.

- Provides consultation and educational materials for NIST employees on managing data and providing public access to results of federally-funded research, including use of the NIST EDI, and the NIST review process, as applicable, for results of federally funded research that are intended for public dissemination. 
- Facilitates search and access to metadata for NIST data or final published articles or NIST Technical Series Publications for the public.

- Supports NIST OU and Office Directors' responsibilities, as applicable

\section{Director, Office of Acquisition and Agreements Management (OAAM)}

- Works with the Directors of NIST OUs and Offices to ensure that activities funded wholly or in part by NIST to a non-NIST organization through a grant, cooperative agreement, contract, or other agreement include requirements for managing data and publications consistently with the NIST directives for Managing Public Access to Results of Federally Funded Research, as specified by NIST in the terms and conditions of the grant, cooperative agreement, contract, or other agreement with the non-NIST organization, beginning October 1, 2015.

\section{Directors of the OUs and Offices that produce scientific data}

- Implements ADLP-approved plan to manage public access to results of federally funded research within his/her OU or Office.

- Works with other offices, e.g., OISM and the Information Services Office, to manage public access to results of federally funded research.

- Reviews data prior to making it publicly available; authority to carry out this responsibility may be delegated to the Division Chief or equivalent.

- Ensures that his/her OU or Office prioritizes the discoverability and publication of applicable OU or Office datasets based on stakeholder needs and resources required.

- Provide oversight for implementation of the OU-/Office-level plan by units (such as divisions, programs, or projects) within the OU/Office.

- Evaluate the effectiveness of units with the OU/Office in meeting the objectives of this plan

- Coordinate with ADLP, ADMR, and CIO in infrastructure planning and implementation to promote interoperability across NIST.

\section{Supervisory Employee within an OU or Office}

- Ensures activities under his/her direction are in compliance with his/her OU or Office plans to manage public access to results of federally funded research.

- Ensures employees under his/her supervision meet employee-level requirements of his/her OU or Office plans to manage public access to results of federally funded research.

- Works with OAAM to ensure that activities funded wholly or in part by NIST to a nonNIST organization through a grant, cooperative agreement, contract, or other agreement include requirements for managing data and publications consistently with the NIST directives for Managing Public Access to Results of Federally Funded Research, as specified by NIST in the terms and conditions of the grant, cooperative agreement, contract, or other agreement with the non-NIST organization, beginning October 1, 2015.

\section{Non-Supervisory Employee}

- Complies with the employee-level requirements of his/her OU or Office plans to manage public access to results of federally funded research: 
- prepares and executes DMPs as specified by the OU or Office plans to manage public access to results of federally funded research, as applicable,

- provides metadata for NIST data to the NIST EDI or other publicly available repositories, as applicable,

- if data are tagged as available to the public in the EDI, provides data in open formats via publicly available repositories or upon request and to the extent feasible, directly to the requestor, free of charge unless otherwise excepted, and

- provides publications dated October 1, 2015 and later to the NIST public access archive system no later than 12 months following publication.

- Works with OAAM to ensure that activities funded wholly or in part by NIST to a nonNIST organization through a grant, cooperative agreement, contract, or other agreement include requirements for managing data and publications consistently with the NIST directives for Managing Public Access to Results of Federally Funded Research, as specified by NIST in the terms and conditions of the grant, cooperative agreement, contract, or other agreement with the non-NIST organization, beginning October 1, 2015.

\section{Awardees and their institutions:}

- Ensure that authors and investigators comply with all terms and conditions of awards, including compliance with the NIST Public Access Policy.

\section{IMPLEMENTATION}

This plan establishes a framework for identifying, managing, and preserving the results of federally funded research so as to make them publicly accessible as peer-reviewed publications and digital data. NIST's guiding principles for implementation include the following:

- Create flexible approaches and infrastructure to accommodate a wide range of results of scientific research as well as a diversity of stakeholders including funded researchers, universities, libraries, publishers, industry, civil society, and any other users of NIST research results. Policies, processes, and infrastructure that provide meaningful access to the results of NIST-funded research for this full range of stakeholders will be developed.

- Optimize search, archival, and dissemination features to encourage innovation in accessibility and interoperability while ensuring long-term stewardship of the results of federally funded research.

- Plan for change as the types and volume of scientific information produced with NIST funding expands. Extensible and evolvable solutions that can accommodate new needs on an ongoing basis are required. NIST will track and respond to continuing changes in digital technologies when planning to make research results publicly accessible.

- Provide appropriate leadership to promote and enhance NIST's reputation for highquality output, willingness to work in partnership, and responsiveness to stakeholders.

\section{Policy}

NIST will adopt a systematic approach to implement a Public Access Policy that includes the following: 
- NIST-wide and OU-/Office-level processes for the continual update and evaluation of public access and data management policies to ensure that these remain effective and relevant into the future and that the evaluation takes into account the relative values of long-term preservation and access and its associated costs and administrative burden.

- Full and open consultation and cooperation with stakeholders, including those in the private sector, through the formation of public-private partnerships with foundations and other research-funding organizations, to improve compatibility and access to publications and data and explore new approaches to maintain and improve NIST's public access and data management policies.

- Public discovery and download of peer-reviewed publications and associated data free of charge no later than 12 months following publication.

- Attribution of publications to authors, journals, and original publishers.

- Effective data management planning for all NIST-funded activities that produce scientific data.

- Public discovery and access to NIST scientific data.

- Clear guidance and access to appropriate education and training materials for NIST staff and NIST-funded extramural researchers to help them comply with NIST policies.

\section{Publications}

NIST will establish a public access archive system to enable the submission of metadata and final, peer-reviewed manuscripts or final publications that includes the following functionalities:

- Allows authors to submit and manage manuscripts directly with the NIST public access archive system or through the funding agreement's NIST Program Official.

- Allows submission by the author, the publisher, or the manager of the funding agreement.

- Accepts manuscripts in a variety of formats compatible with the current state-of the-art in repository architecture.

- Accepts any additional files of figures, tables, data files, or supplementary information included with the manuscript.

- Provides flexible and multiple approaches to manuscript submission.

NIST will partner with the National Institutes of Health (NIH) to utilize the existing PubMed Central (PMC) repository system to serve as the repository of full-text peer-reviewed scholarly publications for NIST, leveraging off of the well-established search, archival, and dissemination features of PMC. The NIST interface to PMC will:

- Enable the storage, organization, and management of metadata and contents of peerreviewed publications and associated data collected or submitted under NIST's Public Access Policy.

- Be established using an architecture and follow industry standards that facilitate open government, enable integration, be machine readable in non-proprietary or widely distributed archival formats, and promote interoperability and accessibility. 
- Have the capacity to integrate peer-reviewed scholarly publications with appropriate scientific databases.

- Be accessible from NIST websites.

- Enable NIST to monitor compliance with the Public Access Policy.

The NIST interface to the PMC public access archive system will ensure easy search, analysis, and download of the full text of peer-reviewed scholarly publications arising from research funded by NIST. Public access to the full text will be provided without charge no later than a 12-month embargo period following publication, although NIST reserves the right to shorten or extend the embargo period. Such an extension would be announced in the Federal Register. Full public access to publications' metadata upon first publication will be provided through PMC in a format that ensures interoperability with current and future search technology. NIST's responsibilities to ensure public access include:

- Properly maintaining the interface system to the PMC archive system to ensure that it is reliably available through the Internet.

- Using existing archives that are trusted, reliable providers of peer-reviewed scholarly and technical literature and are available through the Internet.

- Ensuring that the system is accessible to people with disabilities and compliant with Section 508a of the Rehabilitation Act (29 USC 794d).

- Including the features and capabilities to meet the criteria outlined in the Office of Science and Technology Policy Director's Memorandum dated February 22, 2013.

- Providing annual notice in the Federal Register to allow NIST's customers to petition for changing the embargo period in the following year, for publications in a specific field, by providing evidence that the current embargo period does not provide a public benefit and is inconsistent with the objectives articulated in the OSTP memo.

All of the material available from the PMC site is provided by the respective publishers or authors. Almost all of it is protected by U.S. and/or foreign copyright laws, even though PMC provides free access to it. (Public domain material ${ }^{3}$ is an exception.) Users of PMC are directly and solely responsible for compliance with copyright restrictions and are expected to adhere to the terms and conditions defined by the copyright holder. Transmission, reproduction, or reuse of protected material, beyond that allowed by the fair use principles of the copyright laws, requires the written permission of the copyright owners. U.S. fair use guidelines are available from the U.S. Copyright Office at the Library of Congress. ${ }^{4,5}$

PMC has two services that may be used for automated retrieval and bulk downloading of a subset of articles and all the metadata from the PMC archive. The PMC Open Archives Initiative (OAI) service and the PMC File Transfer Protocol (FTP) service are the only services that may be used for automated downloading of articles in PMC and only a subset of the total PMC content, the PMC Open Access Subset ${ }^{6}$, is included. Publishers can set licenses allowing

\footnotetext{
${ }^{3}$ http://www.ncbi.nlm.nih.gov/pmc/about/copyright/\#public-domain

${ }^{4}$ For fair use guidelines, see http://www.copyright.gov/fls/fl102.html

${ }^{5}$ For more information, see http://www.ncbi.nlm.nih.gov/pmc/about/copyright/.

${ }^{6}$ http://www.ncbi.nlm.nih.gov/pmc/tools/openftlist/
} 
bulk download when they send final published articles directly to PMC. (Articles that are available through the PMC OAI and FTP services are still protected by copyright but are distributed under a Creative Commons or similar license that generally allows more liberal use than a traditional copyrighted work.)

By partnering with the NIH and its established PubMed Central publication archive, NIST ensures the permanent preservation and long-term accessibility of metadata and its peerreviewed scholarly publications free of charge.

NIST will take a staged approach to providing public access to publications via PMC. A pilot exercise, which will include the NIST Journal of Research and the Journal of Physical and Chemical Reference Data, will be conducted in year one, establishing the infrastructure for transferring metadata and publications to the repository. In year two, deposit of NIST-authored peer-reviewed publications will be operational. In year three, extramural publications of scientific research funded wholly or in part by NIST will be deposited.

\section{Data}

To the extent feasible and consistent with applicable law and policy, agency mission, resource constraints, U.S. national, homeland, and economic security, and the objectives listed above, digitally formatted scientific data resulting from unclassified research supported wholly or in part by Federal funding will be stored and publicly accessible to search, retrieve, and analyze.

NIST's plan for providing public access to data consists of three components: data management plans (DMPs), an Enterprise Data Inventory (EDI), and a Common Access Platform providing a public access infrastructure. Work began with a pilot implementation developed according to the guidance provided in the Project Open Data component of OMB memorandum M-13-13 and the deadline it set of November 9, 2013 for initial implementation. This pilot was initiated with a review of NIST reference data and the selection of an appropriate pilot set representative of the diversity of data types and domains across NIST. Persistent identifiers and metadata have been provided for some of this reference data, and the work is continuing. Lessons learned in this pilot will inform the development of NIST's Enterprise Data Inventory (EDI), described below.

Generation of data management plans has also begun, providing documentation of plans for storage, archival, and accessibility for NIST's multiple types of data. At a minimum, data management plans (DMPs) must contain a summary of activities that generate data, a summary of the data types generated by the identified activities, a plan for storage and preservation of the data, and a plan describing whether and how data generated will be reviewed and made available to the public.

The EDI is a catalog of the datasets that are generated via NIST-sponsored research to enable researchers to link those datasets to the scientific literature, other datasets, etc. The metadata describing the scientific data contained in the catalog will include, at a minimum, the common core metadata schema in use by the federal government, found at https://project-opendata.cio.gov/. This catalog is part of the comprehensive public listing of agency data that was required by the Executive Order of May 9, 2013 and OMB Memorandum M-13-13. The JSON file for the current public listing of datasets is provided at http://www.nist.gov/data/index.cfm; 93 NIST datasets are currently available via data.gov, including a complete listing of NIST Standard Reference Data (SRD), which has been critically evaluated using documented procedures under the requirements of the Standard Reference Data Act. The NIST EDI serves 
not as a repository of study data but as an index containing information that describes a data set (i.e., metadata) and information about where and how to access the data. An interagency technical advisory group has been assembled to provide input to this effort and ensure that the reference implementation meets the needs of a wide range of stakeholders.

The final component, the Common Access Platform (CAP), will use the information gained in the first two phases to put in place production-level infrastructure and populate it with persistent identifiers and metadata for all publicly available NIST data. The CAP is expected to provide for interoperability within NIST and potentially with other federal agencies. This production infrastructure will be subject to continuing evaluation, refinement, and revision. NIST will assess the long-term needs for preservation of scientific data in fields that the agency supports, and outline options for developing and sustaining repositories for scientific data in digital formats, taking into account the efforts of public- and private-sector entities.

All grants, contracts, and cooperative agreements will include requirements for data management planning consistent with the goals of the NIST plan. Terms and Conditions will include language that requires scientists seeking funding to describe how and where they will make their data available to the public and explicitly describe how they will make the data that underlies scientific publications available for discovery, retrieval, and analysis.

\section{Outreach and Education}

In coordination with other agencies and the private sector, awareness and support training, education, and workforce development related to NIST's plans to provide public access to the results of federally funded scientific research, including scientific data management, analysis, storage, preservation, and stewardship, will be provided to NIST staff and those outside NIST who are working on NIST-funded scientific research.

\section{METRICS, COMPLIANCE, AND EVALUATION}

NIST will develop metrics that evaluate compliance with NIST's Public Access Policy.

Possible metrics include:

- Number of intramural and extramural papers (i.e., articles submitted from NIST grants and contracts) made available to the public per year,

- Percentage of intramural and extramural papers for which datasets were made available immediately upon publication,

- Percentage of intramural and extramural papers available in full text after the embargo period, per year,

- Number of datasets added to the Enterprise Data Inventory per year.

- Number of datasets made public per year.

- Percentage of staff and grantees in compliance with requirements.

NIST will utilize data from PubMed Central, other reference sources, grant and cooperative agreements, and contract reports to determine compliance; compliance will be enforced through annual performance reviews at both staff and management levels.

DMPs of extramural scientists seeking funding will be evaluated, and the quality of DMPs will be considered in funding decisions. 


\section{PUBLIC-PRIVATE PARTNERSHIP}

NIST will take advantage of PubMed Central, which is an existing and accepted public-private partnership. Its primary means of disseminating the results of federally funded research is through private, peer-reviewed journals rather than through reports published by the federal government. The use of a non-proprietary archival language maximizes interoperability between public and private platforms, making creative reuse of metadata and contents of publications possible. The same potential for reuse exists for NIST's data and associated metadata. Value to all stakeholders is enhanced, and unnecessary duplication of existing mechanisms is avoided. The impact of federal research investments is maximized through public access to the results of that research.

\section{INTERAGENCY COORDINATION}

NIST will coordinate with other agency partners through the following mechanisms.

- $\quad$ NIST is participating in the interagency publications and data implementation working groups convened by OSTP to enable interagency coordination in responding to the requirements of the February 2013 public access memo.

- NIST is an active participant in the Federal Networking and Information Technology Research and Development (NITRD) program, including the Big Data Senior Steering Group. More than 15 Federal agencies and offices currently participate in the Senior Steering Group and its sub-groups for data technologies, research projects, challenges and competitions, and workforce development.

- NIST has established an interagency Technical Advisory Group to provide input on the pilot Common Access Platform reference implementation for integrated access to distributed data repositories (see section 7 above).

- NIST is coordinating with NIH for the use of the PubMed Central publications repository and adherence to established PubMed Central requirements.

- NIST will explore the development of a research data commons, a federated system of research databases, along with other Departments and Agencies for storage, discoverability, and reuse of data with a particular focus on making the data underlying the conclusions of peer-reviewed scientific publications resulting from federally funded scientific research available for free at the time of publication.

\section{PUBLIC NOTICE}

NIST will work with other executive agencies in publishing a generalized announcement of the public access plan in the Federal Register soliciting comment from federally funded researchers, universities, libraries, publishers, users of federally funded research results, civil society groups and the general public. NIST will post its final Public Access Plan for public comment on the NIST website.

\section{UPDATE AND RE-EVALUATION OF THE PLAN}

The plan will be evaluated annually and updated as necessary until NIST's Public Access Policy is implemented. 


\section{TIMELINE FOR IMPLEMENTATION}

Key milestones are outlined in each implementation category below.

\begin{tabular}{|c|c|c|c|}
\hline & & DATA & PUBLICATIONS \\
\hline \multicolumn{4}{|c|}{ POLICY } \\
\hline FY13 & August 2013 & Submit draft plan to OSTP & Submit draft plan to OSTP \\
\hline FY14 & March 2014 & Feedback received from OSTP & Feedback received from OSTP \\
\hline FY14 & May 2014 & \multicolumn{2}{|c|}{ Submit revised draft plan (data and publications combined) to OSTP } \\
\hline FY14 & June 2014 & \multicolumn{2}{|c|}{ NIST staff review of NIST Public Access Plan } \\
\hline FY15 & December 2014 & \multicolumn{2}{|c|}{ NIST Public Access Policy effective } \\
\hline FY15 & December 2014 & \multicolumn{2}{|c|}{ NIST Public Access Plan posted for public review } \\
\hline FY15 & January 2015 & \multicolumn{2}{|c|}{$\begin{array}{l}\text { Address public comments in NIST Public Access Plan and Policy, as } \\
\text { appropriate }\end{array}$} \\
\hline \multicolumn{4}{|c|}{ INFRASTRUCTURE } \\
\hline FY13 & August 2013 & $\begin{array}{l}\text { Data Management Plan (DMP) } \\
\text { template drafted }\end{array}$ & \\
\hline FY14 & November 2013 & $\begin{array}{l}\text { Initial pilot Enterprise Date } \\
\text { Inventory (EDI) system } \\
\text { operational per OMB M-13-13 }\end{array}$ & $\begin{array}{l}\text { Letter of Intent submitted to NIH } \\
\text { to utilize PubMed Central as NIST } \\
\text { repository }\end{array}$ \\
\hline FY14 & February 2014 & $\begin{array}{l}\text { Initial draft of NIST extensible } \\
\text { metadata schema for scientific } \\
\text { data }\end{array}$ & \\
\hline FY14 & May 2014 & DMP Tool demo development & $\begin{array}{l}\text { Draft Business Process for internal } \\
\text { Editorial Review System }\end{array}$ \\
\hline FY14 & June 2014 & & $\begin{array}{l}\text { Draft reviewed by Editorial } \\
\text { Review Boards and NIKE } \\
\text { working group }\end{array}$ \\
\hline FY14 & July 2014 & $\begin{array}{c}\text { Develop metadata registry and } \\
\text { handle resolver for Common } \\
\text { Access Platform (CAP) }\end{array}$ & \\
\hline FY14 & August 2014 & Full DMP Tool development & $\begin{array}{c}\text { Interagency Agreement with NIH } \\
\text { established for deposit of peer- } \\
\text { reviewed publications in PubMed } \\
\text { Central }\end{array}$ \\
\hline
\end{tabular}




\begin{tabular}{|c|c|c|c|}
\hline & & DATA & PUBLICATIONS \\
\hline FY15 & November 2014 & $\begin{array}{c}\text { Develop data-type registry for } \\
\text { CAP }\end{array}$ & $\begin{array}{c}\text { Pilot for depositing example } \\
\text { journal types to PubMed Central } \\
\text { established }\end{array}$ \\
\hline FY14 & September 2014 & $\begin{array}{l}\text { Demonstrated EDI concept to } \\
\text { Data Policy Group and stood up } \\
\text { EDI Customers Working Group }\end{array}$ & $\begin{array}{l}\text { Processes and plans developed to } \\
\text { facilitate submission of NIST- } \\
\text { authored journal articles to NIH } \\
\text { PubMed Central. }\end{array}$ \\
\hline FY15 & December 2014 & $\begin{array}{l}\text { Data citation recommendations } \\
\text { made }\end{array}$ & \\
\hline FY15 & December 2014 & \multicolumn{2}{|c|}{$\begin{array}{l}\text { Standard language developed Terms and Conditions for grants and } \\
\text { contracts }\end{array}$} \\
\hline FY15 & February 2015 & $\begin{array}{l}\text { Enterprise Data Inventory (EDI) } \\
\text { operational }\end{array}$ & \\
\hline FY16 & October 2015 & $\begin{array}{l}\text { Common Access Platform (CAP) } \\
\text { operational }\end{array}$ & $\begin{array}{l}\text { Editorial Review System for } \\
\text { publications operational }\end{array}$ \\
\hline
\end{tabular}

\begin{tabular}{|c|c|c|c|}
\hline \multicolumn{4}{|c|}{ PROCESSES } \\
\hline FY15 & October 2014 & $\begin{array}{l}\text { Data Management Plans required } \\
\text { for all NIST-funded research }\end{array}$ & \\
\hline FY15 & February 2015 & $\begin{array}{c}\text { Metadata for publicly available } \\
\text { datasets entered into EDI (and } \\
\text { datasets shown in data.gov as } \\
\text { appropriate) }\end{array}$ & \\
\hline FY16 & October 2015 & \multicolumn{2}{|c|}{$\begin{array}{l}\text { Standard language regarding public access to data and publications } \\
\text { included in Terms and Conditions for grants and contracts }\end{array}$} \\
\hline FY16 & October 2015 & & $\begin{array}{c}\text { Submission of NIST intramural } \\
\text { journal articles to repository is } \\
\text { operational }\end{array}$ \\
\hline FY17 & October 2016 & & $\begin{array}{c}\text { Submission of NIST extramural } \\
\text { journal articles to repository is } \\
\text { operational }\end{array}$ \\
\hline
\end{tabular}




\begin{tabular}{|c|c|c|c|}
\hline & & DATA & PUBLICATIONS \\
\hline \multicolumn{4}{|c|}{ OUTREACH AND EDUCATION } \\
\hline FY14 & October 2013 & $\begin{array}{l}\text { Information and input web site } \\
\text { launched }\end{array}$ & \\
\hline FY14 & December 2013 & $\begin{array}{c}\text { Pilot OU Town Hall outreach } \\
\text { event }\end{array}$ & \\
\hline FY14 & September 2014 & $\begin{array}{l}\text { Initial educational resources in } \\
\text { place }\end{array}$ & $\begin{array}{l}\text { NIST Town Hall meeting, NIST } \\
\text { Connections articles, FAQs on } \\
\text { internal website }\end{array}$ \\
\hline FY15 & December 2014 & $\begin{array}{c}\text { Pilot training session(s) to get } \\
\text { feedback on EDI }\end{array}$ & \\
\hline FY15 & September 2015 & & $\begin{array}{c}\text { NIST Town Hall meeting, NIST } \\
\text { Connections articles } \\
\end{array}$ \\
\hline FY16 & October 2015 & & $\begin{array}{l}\text { Meetings with individual awardees } \\
\text { and NIST contacts to discuss } \\
\text { public access to research data and } \\
\text { publications generated via grants } \\
\text { and contracts }\end{array}$ \\
\hline
\end{tabular}

\section{RESOURCES}

NIST has identified base funding resources within its Scientific and Technical Research and Services Appropriations in order to ensure initial implementation, scale-up, and continued operation of the NIST system to make publications and data publicly available.

\section{DOCUMENT HISTORY}

Draft approved by OSTP and OMB, 04 December 2014

Plan posted to www.nist.gov/data, 03 April 2015 
Appendix A. Members of the committees responsible for drafting NIST's plan for providing public access to results of federally funded research.

\section{Data Policy Group}

Chair - Wo Chang

Laboratory Programs - Dianne Poster

Center for Nanoscale Science and Technology - Mark Stiles

Engineering Laboratory - Kirk Dohne

Information Technology Laboratory - James St. Pierre, Kathleen Roberts

Material Measurement Laboratory - John Henry Scott

NIST Center for Neutron Research - Robert Dimeo, Alan Munter

Office of Information Systems Management - Susannah Schiller

Physical Measurement Laboratory - James Olthoff, Aaron Fein

Program Coordination Office - Heather Evans, Jason Boehm

Special Programs Office - James Whetstone, Katherine Sharpless

Standards Coordination Office - Sally Bruce

\section{Publications Working Group}

Chair - Katherine Sharpless

Laboratory Programs - Donna Kimball

Information Services Office - Barbara Silcox, Regina Avila

Office of Information Systems Management - John Venable, Joseph Kau

Public Affairs Office - Virginia Covahey 
Appendix B. Feedback received from NIST staff's review of draft Public Access Plan and responses provided by the Data Policy Group.

\section{It seems NIST's Public Access Plan is not extensive enough and does not fully address the ambitious goals and spirit set by OSTP. NIST should do much more.}

It is true that the White House directives set out some very ambitious goals for Federal agencies. NIST is committed to meeting these goals, by phasing in new systems and requirements over the coming years. To enhance NIST's current methods of making research data and scientific publications available through various mechanisms (e.g., journals, FTPs, NIST website, etc.), NIST plans to systematically

- identify available datasets by creating Data Management Plans (DMPs) in which consequence levels for data preservation, review, and discoverability by applying the NIST Data Taxonomy will be mapped,

- assign and link persistent identifiers (PIDs) to all publications and datasets

- develop the NIST Enterprise Data Inventory (EDI), which will provide a metadata catalog containing the dataset descriptions - allowing discovery and access - and a type registry that describes the dataset content and structure, and

- deposit NIST scientific publications (and associated data if available) in PubMed Central and the Federal Digital System (FDSys), two well-established repositories.

\section{The NIST Public Access Plan does not comply with the OSTP and OMB memos that} state that all research data related to a publication must be open, machine-readable, and digitally accessible to the public at the time of publication.

Under our plan, NIST articles and reports will be discoverable through Google, Google Scholar, FDsys and PubMed Central (PMC), and scientific/technical article databases. A search mechanism that searches both FDsys and PMC will be available from the NIST website. One of the goals of the OSTP requirement is to provide free access to federal research results to the public at large, not just to other scientists who are experienced in conducting literature searches, therefore it is important that publications be discoverable in multiple ways. Supplementary information and datasets associated with publications can be stored with publications in both FDsys and PMC. Workflows are currently under development. Metadata will be available as soon as a paper is published. After a paper is published, the link to the publisher's website via the digital object identifier (DOI) is provided on the PMC site and readers will be able to access the paper via this link if the publisher permits access.

Furthermore, by implementing the Common Access Platform (CAP) with persistent identifiers (PIDs), the PID can be open, machine-readable, and digitally accessible and provide very fine granularity for:

a. Data value - provide syntactic and semantic definition of a data point: e.g., a spreadsheet cell contains the value 32, which is an integer with description for degrees "in Celsius".

b. Dataset - provide information such as a general description of the data, content structure, application program interface (API) to access dataset, etc.

c. Data repository - provide information for access rights, what network protocol is used, etc. 
Therefore, the CAP can support any standard and proprietary digital format. Once the datasets are being assigned a persistent identifier (PID), publications can easily make reference to related datasets using PIDs just like DOIs.

As the NIST Public Access Plan takes effect, and the above-mentioned infrastructure is in place, NIST laboratories should also be considering how to improve our ability to provide open, machine-readable research data. This effort will require OU leadership to provide additional resources and guidance for prioritization based on factors including the reasonableness of effort and the stakeholder need.

3. Based on the NIST Public Access Plan, it appears that NIST will be behind other agencies in providing open access to publications and data, and does not take advantage of expertise and knowledge available in other agencies.

NIST is coordinating the Interagency Technical Advisory Group (iTAG) with other Federal agencies (DOE, National Archives and Records Administration, Smithsonian, Treasury, Census) for gathering operational requirements and insights on how we can maximize access to scientific and technical data. The objective is to improve the public's ability to locate and access appropriate digital assets while enabling proper long-term stewardship of these assets by optimizing archival functionality and (where appropriate) leveraging existing institutional repositories, public and academic archives, and community and discipline-based repositories of scientific and technical data, software, and publications.

4. The NIST Public Access Plan seems to be focused on the researchers and data generators and not the data consumers or other beneficiaries of the plan. Specifically, are researchers the best choice for gatekeepers who decide which data will be discoverable? It is important to consider the consumers of NIST data as we implement the NIST public access plan. The purpose of the plan and associated documents such as the Data Taxonomy is to provide direction and guidance to NIST researchers. Planning for the management and sharing of NISTgenerated data is an individual responsibility. The OU directors and their management teams are responsible for deciding which categories of data will be discoverable, and this will vary from OU to OU using the taxonomy as a starting point for discussion. However, as stated in the taxonomy and plan, OUs must consider stakeholder needs when prioritizing which data sets to make publicly available.

5. The NIST Public Access Plan does not provide a solution that will permit NIST data to be discovered across different scientific domains.

By using the CAP architecture with PIDs as the basic fabric for research data and scientific publications, NIST has the unique opportunity of integrating all NIST's internal and external scholarly publications, technical reports, scientific data, and even software for discoverability and consumption within as well as across domains. Furthermore, the CAP architecture also enables federation of datasets between other agencies' datasets once these datasets are also associated with PIDs.

6. The NIST Public Access Plan does not provide a solution that will interoperate with the mainstream infrastructure in the field of scholarly publications, e.g., integration with CrossRef. 
When NIST authors submit an article for publication in a journal, publishers participating with CrossRef acquire the information that is necessary for use of CrossRef, FundRef, and OrcID. That information is obtained regardless of where (or whether) an author's copy of the paper is placed in a repository. The version of record (the publisher's version with the DOI) will still be available directly from publishers' websites. Access to NIST publications will be possible in two ways: (1) the way it occurs now (which is essentially the same approach as provided by CHORUS) whereby a reader can access the citation and possibly the article itself if that is permitted by the publisher and (2) via PMC or FDSys.

\section{CHORUS would be a better publication repository than PubMed Central because it is} free to NIST, requires no additional work by authors, provides proper indexing for searches, and provides the publisher's version of record to readers.

CHORUS and PMC are complementary tools by which we can make our publications available, and it is likely that we will use both. We have met with representatives of CHORUS several times to discuss options. CHORUS is a portal to publishers' websites. While CHORUS provides citation information and a link to the journal, access to the content of the article can often only be obtained by paying a toll (i.e., if a library subscribes to the journal, if the reader pays to obtain a copy of a paper, or if the author has paid to make the paper open access) or by waiting out an embargo. By using PMC and FDSys as our repositories, we can make the content of papers immediately available if all of the papers' authors are federal employees. (Some journals allow federal employees to deposit the version of record in agency repositories.) Because of the possible limited access to publications via CHORUS, NIST - like other federal agencies including DOE - will also make publications available through a separate repository (PMC for peer-reviewed papers, FDSys for NIST Publication Series and non-peer-reviewed papers). DOE funds their own repository; NIST has established an interagency agreement with $\mathrm{NIH}$ so that we can use their repository rather than establishing one of our own.

NIST's editorial review processes and requirements are currently being updated. An Editorial Review System to replace Nike is being sought, and authors will have to update citation information and upload final, peer-reviewed versions of their papers to the new system, just as they are required to do now. Depending on a given publisher's agreement with PMC and/or NIST, the publisher may deposit the published version or the author's version with PMC, or the NIST library will do so. PMC clearly marks papers to distinguish the author's and final published versions. Authors will not upload papers to PMC. NIST will index publications in FDsys and PMC so that papers in both repositories can be found in a single search.

The logical endpoint of the work that we do using federal funds is to make results of the work available to those who have paid for it. In the past, we ordered reprints; more recently, we might have paid a publisher to provide open access to a paper. We can continue to do that, making the content of papers available on the publishers' websites and accessible via CHORUS. We can also post papers (as copyrights permit) to other websites. But papers will also be available through PMC and FDSys. The only expected additional cost in terms of authors' time will be that associated with the review of XML-formatted manuscripts in PMC. 


\section{The NIST Public Access Plan takes effect in October 1, 2014, but the plan does not state clearly what this means for data. The NIST Public Access Plan has a phase-in period for publications but not for data. Is this approach realistic?}

NIST will proceed in three phases to implement NIST Public Access Plan. The first phase is the implementation of Data Management Plans (DMPs). All data generated beginning October 1, 2014 must be covered by a DMP that contains a minimum of four elements: (a) a summary of data-generation activities, (b) a summary of data types, (c) plans for an appropriate level of data preservation, and (d) a description of the appropriate level of data access. The NIST laboratories will be responsible for implementing a system for generating DMPs, which may include the use of an online tool developed by OISM. For questions about each laboratory's requirements for generating DMPs, contact your DPG representative (http://inet.nist.gov/adlp/howdoi/publicaccess.cfm).

Phase two involves the Enterprise Data Inventory (EDI). To help make our data more discoverable, during FY 2015, NIST will generate a catalog of our datasets, housed within the new EDI. It will consist of metadata (i.e., descriptions) of discoverable NIST datasets. Laboratory-specific guidelines will help NIST staff determine which datasets should be listed in the EDI. If you are interested in participating in testing the EDI, contact NIST Data Coordinator Wo Chang (wo.chang@nist.gov). As datasets are discovered and we learn more about our customers' needs, we will prioritize datasets for availability through a publicly accessible repository. As the NIST Public Access Plan takes effect, making actual datasets (and associated domain-specific metadata) available online will require OU leadership to provide additional resources and guidance for prioritization based on factors including the reasonableness of effort and the stakeholder need.

The final phase is that publications will be made freely available. All NIST scholarly and technical publications with a publication date of October 1,2015 or later must be submitted to the NIST public-access archive system within 12 months following publication. During FY 2015 this system will be developed and piloted. The initial pilot will focus on inclusion of two journals - the NIST Journal of Research and the Journal of Physical and Chemical Reference Data - into the public-access archive system. Other journals will be added to the archive over the course of FY 2015. Publications resulting from NIST-funded grants will be deposited in the archive beginning October 1, 2016. If you are interested in participating in the pilots, contact Open Access Officer Katherine Sharpless (katherine.sharpless@nist.gov).

\section{How will the requirements for DMPs be implemented?}

OU directors are responsible for implementing DMPs within their organizations. Some laboratories already have program and project management tools in place that will integrate DMP content, others may choose to use the online tool that OISM is developing, and some laboratories may determine that they will build a new collection tool. For OU-specific DMP implementation, please contact your supervisor or your OU DPG representative (http://inet.nist.gov/adlp/howdoi/public-access.cfm).

\section{Are guest researchers covered by NIST Public Access Plan?}

Yes, providing public access will be a NIST policy, and guest researchers agree to abide by NIST policies when they sign their guest researcher agreements. 


\section{How will data that is generated by collaborators or research partners outside of NIST}

be treated under this plan?

The project lead will be responsible for determining how data will be treated. NIST will not release datasets that have been generated by a collaborator unless both parties are in agreement. Similarly, in cases where multiple OUs work together on a common activity, the OU with the main role in directing the activity has discretionary authority to manage the DMPs and associated data. In the case of grant recipients, expectations for data management will be addressed by language in Terms and Conditions, which is currently under discussion.

12. Is deposition of data into a repository required by NIST Public Access Plan, either for NIST staff or for our external collaborators or partners? Will NIST stand up data repositories for this plan? If so, will they be on-premises, associated with the publications repositories, or elsewhere? No repository exists at NIST to repose or disseminate scientific data in digital formats, nor does NIST have a plan to provide one.

If data has been categorized as discoverable, it must be made available. At this time, that might occur through a deposit in PubMed Central or in FDSys as supplementary information associated with a publication, posting on the NIST website, or by requiring a direct request to the NIST researcher who is responsible for the data. Data usage and requests for datasets will allow us to identify and prioritize data that should be added to repositories, and will allow us to develop our own repositories as appropriate. A centralized data repository is currently being explored; a detailed procedure on how to deposit datasets is still in development.

\section{What is the dividing line between data and metadata?}

Data is 'recorded factual material commonly accepted in the scientific community as necessary to validate research findings.' Metadata (administrative) is the information that would allow you to locate that data, much like a card catalog was once used to locate a book in a library. Domainspecific metadata (description of conditions experiment under which the data or modeling result were generated) are not part of the administrative metadata.

\section{Metadata creation or capture can be a very time intensive operation. What resources} are being deployed at NIST to assist NIST staff with this task?

The goal of the NIST Public Access Plan is to minimize administrative burden on staff researchers while being responsive to White House directives. OMB has developed the Common Core, a minimum set of required metadata, which is used to catalog datasets generated by the funded agency; note that this is not an instrument-level, domain-specific repository but is administrative metadata that describes the datasets (e.g., title and description of dataset, name and contact information of responsible staff member) and information about where and how to access the data through a simple interface. The oversight implementation of the EDI, including approval chains, will be developed in the coming months and communicated to all staff.

\section{How will data be reviewed by ERB? There are no details on how review of data will be} implemented.

The technical quality of the data itself is the responsibility of the creator, producer and/or distributor; its review is delegated to the OU that created, produced, and/or distributes it. ERB will be responsible for review of associated documentation. Examples: 
(1) Information about SRD 100 is located at http://www.nist.gov/srd/nist100.cfm. ERB did not review the webpage or SRD 100 itself but did review the user's guide, which is available from the SRD 100 page and at http://www.nist.gov/srd/upload/Users-GuideSESSA-Version-1-3.pdf.

(2) A paper is published with data provided as supplementary information. ERB would review the entire publication 'package' as they normally do. The supplementary information would be checked by the ERB sponsor (and by other reviewers) to confirm that it met NIST editorial and policy requirements (e.g., SI usage, appropriate uncertainties), but the data itself would not be closely examined by the ERB sponsor or the board. Technical review is conducted at the group and division levels and by ERB readers.

16. Where can I learn more about the NIST-XM metadata requirements?

The Data Dictionary for NIST Extensible Metadata Scheme is based on the OMB Common Core, available at http://project-open-data.github.io/schema/. The NIST dictionary is awaiting finalization of the OMB recommendations.

17. The NIST data taxonomy is not actually a taxonomy, but rather a description of NIST data types.

Dictionary.com defines taxonomy as "a classification into ordered categories" and we believe that is, in fact, what the NIST data taxonomy is.

18. A list of examples for each category in the NIST data taxonomy would be helpful. Some examples of each type of data:

- Standard Reference Data - defined by Standard Reference Data Act; see http://www.nist.gov/srd/

- Reference Data - for example, see http://www.nist.gov/pml/data/index.cfm or special datasets that NIST provides on the SRD website

- Resource Data - data used to develop an economic impact report, http://www.nist.gov/director/planning/upload/report03-1.pdf

- Published Results - results provided in a published paper or on a website or in a publicly available dataset

- Publishable Results - results of an analysis that are provided in a management-reviewed report that is intended for internal use only

- Derived Data - peak areas obtained through integration of raw data, concentrations that those peaks represent

- Working Data - raw data coming off an instrument

19. The delineations between some of the data categories in the NIST data taxonomy are unclear, and some appear to overlap each other.

Yes, the delineations between some of the categories are meant to be flexible. The OUs will determine which of their datasets fit into which category.

20. Using a data classification system such as provided in the NIST data taxonomy may not be practical in the long term.

The data taxonomy is a starting point, and it can be modified if that should be necessary. 
21. In the section on consequence levels, the classes are referred to as "grades of data", which along with the triangular nature of the diagram may provide a false impression of a data quality hierarchy.

The second paragraph of the Taxonomy document states that although the taxonomy takes the form of a pyramid, the categories are not strictly hierarchical.

22. What levels of data in the data taxonomy are intended for public release?

The data taxonomy outlines minimum discoverability requirements for NIST data, based on the seven NIST data types (figure 4). However, these are minimum, or baseline, requirements that are a starting point for OUs to make decisions about data set discoverability. The data taxonomy does not explicitly discuss public release of data, but datasets that are listed in the EDI must be made publicly available unless they are identified in the EDI as restricted for public release.

23. The consequence levels for preservation appear to address only data backup, not true preservation methods, and they appear to be redundant with existing NIST IT Security plans.

Although there appears to be redundancy with NIST IT Security plans, we have learned that not all NIST researchers are backing up their data. The preservation consequence levels should reinforce the need to do that. We understand that there is a difference between backup and preservation, but depending on the requirements established within the OUs, backup may be all that is necessary for some types of data.

24. The discoverability consequence levels require a PID be applied to some unpublished data. Since most of this data will reside on NIST-internal IT systems, won't this be a problem?

The PID is a pointer to a location of the data, which can be updated if the data are moved to a NIST IT system designed for public access.

25. How will data usage statistics (e.g., views/downloads/use) be tracked and then attributed (i.e., like citations to a journal)? Will these be included in the performance evaluation process?

This is still being discussed but data management plans will be considered in the context of performance reviews.

26. The NIST response to the OSTP states that it will be posted for review in July 2014 and that public comments will be addressed in September 2014. Isn't this timeline unrealistic? We are slightly behind schedule as we await OMB's review of our draft plan.

27. Section 14 of the NIST response to the OSTP states that sufficient resources exist at NIST to implement the plan on an ongoing basis, but the plan does not provide cost estimates for implementation. Is it appropriate to make this statement?

The NIST Director will ensure that resources are available for implementation of the plan. 
Appendix C. Public feedback received in response to the Federal Register Notice of July 7 , 2015.

$\begin{array}{cl}\text { Comment Number } & \text { Submitter } \\ 1 & \text { American Society of Mechanical Engineers (ASME) } \\ 2 & \begin{array}{l}\text { Association of American Publishers (AAP) and International Association } \\ \text { of Scientific, Technical, and Medical Publishers (STM) }\end{array} \\ 3 & \text { Clearinghouse for the Open Research of the United States (CHORUS) } \\ 4 & \text { Inside Public Access } \\ 5 & \text { Jean Public } \\ 6 & \text { John Wiley \& Sons } \\ 7 & \text { RELX Group }\end{array}$


Sharpless, Katherine E.

From:

Sent:

To:

Cc:

Subject:

Attachments:
Kathryn Holmes <HolmesK@asme.org>

Thursday, August 20, 2015 3:10 PM

Sharpless, Katherine $\mathrm{E}$.

Philip DiVietro

National Institute of Standards and Technology Plan for Providing Access to the Results of Federally Funded Research (Federal Register Doc. 2015-16508)

ASME Comments on NIST Public Access Plan.pdf

Dear Ms. Sharpless,

Please find attached a letter from ASME responding to your request for comments on the "National Institute of Standards and Technology Plan for Providing Access to the Results of Federally Funded Research" (Federal Register Doc. 2015-16508).

Please contact us if you have any questions.

Warm regards,

Kathryn

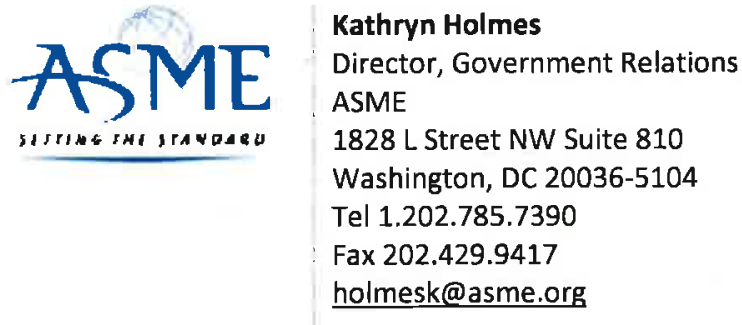

Connect with me on ASME.org 
August 20, 2015

Katherine Sharpless

National Institute of Standards and Technology

100 Bureau Drive Stop 4701

Gaithersburg, MD 20899-4701

Re: National Institute of Standards and Technology Plan for Providing Access to the Results of Federally Funded Research (Federal Register Doc. 2015-16508)

Dear Ms. Sharpless:

ASME appreciates the opportunity to comment on the National Institute of Standards and Technology (NIST) Plan for Providing Access to the Results of Federally Funded Research (Federal Register Doc. \#2015-16508.)

With over 140,000 members, ASME (the American Society of Mechanical Engineers) is the largest mechanical engineering professional organization in the world. Since its founding in 1880, ASME has worked to advance public safety and the quality of life throughout the world. ASME's reputation as a "neutral convener" has been earned over these many decades by its deliberate embrace of all stakeholders in the consensus process and in facilitating a robust technical peer review process built on integrity and honesty.

ASME publishes 29 technical journals periodically highlighting the latest engineering research. Our organization annually publishes about 3,500 journal articles each year, authored by approximately 9,000 authors and researchers, many of whom are US researchers who acknowledge support from the US government. All of which are reviewed by some 7,500 subject matter expert editors and reviewers. ASME journals offer the highest quality peer-reviewed literature in their respective field of mechanical engineering. In terms of conferences proceedings, ASME publishes some 8,000 papers annually, representing the work of some 20,000 authors and the involvement of some 15,000 subject matter expert organizers and reviewers.

ASME endorses the dissemination of the results of all peer-reviewed research, including research supported by federal funding, but it must be done in a manner that is sustainable for the publishing community. It is critical to protect the authors' rights to their intellectual property, as well as the critical functions of peer review. Over the years, our organization has invested in technologies and innovations that enable and preserve high-quality digital peer review, production, distributions, interoperability and discovery of the latest scientific and scholarly works.

ASME, along with over 400 other members of the scholarly and professional publishing community, is a member of the Association of American Publishers (AAP). AAP has submitted comments to NIST providing detailed responses to the questions raised in your Request for Comments. We strongly endorse their letter and are in agreement with their recommendations, although we would like to elaborate on two of the challenges associated with implementing public access.

Federal investments in scientific research are vital contributors to our nation's economy and our national security. For decades, the U.S. has reaped the benefits of effective public-private partnerships. The best approach for 
Katherine Sharpless

August 20, 2015

Page 2

achieving greater public access for federally funded research is to continue to support public-private partnerships which will result in the broad dissemination of materials that analyze and interpret research while preserving the critical peer reviewed material, which is considered the "gold standard" of scientific communication and content

We urge you to partner with us in participating in the Clearinghouse for Open Research of the United States (CHORUS), a multi-publisher portal providing access to journal articles reporting on government-funded research. ASME, along with over 100 scholarly publishers, is a member of CHORUS which leverages existing infrastructure, tools, and services that support sharing, access, discoverability, reporting, and preservation. CHORUS also reduces the compliance burden on authors, and in turn increases compliance with public access goals.

ASME, along with the other scholarly publishers who are engaged in CHORUS, would welcome the opportunity to develop a partnership with NIST that would provide access to federally funded, peer reviewed research articles, while preserving the scholarly value of the peer reviewed version of record and maintaining an ever-growing archive in perpetuity. CHORUS would advance access without any new federal investments or burdensome requirements on researchers or their institutions. The U.S. Department of Energy (DoE) is currently utilizing CHORUS as a component of its model for providing public access to peer-reviewed articles that report on DOEfunded research.

We appreciate that your plan also provides an opportunity to be able to petition to lengthen embargo periods, as well as your recognition of the need to "effectively promote the quality and sustainability of scholarly publications while meeting the objectives of public access." In the comments provided by AAP, they provide various examples of evidenced based research, but a study that was prepared by Dr. Philip Davis entitled "Journal Usage Half-Life," specifically addresses usage half-lives of journals both within and across subject disciplines, including engineering. As stated in his study, "Just 3\% percent of journals had usage half-lives of 12 months or less, which ranged from as low as $1 \%$ for Life Sciences Journals to as high as $6 \%$ for Engineering journals." Dr. Davis analyzed usage data of more than 2,800 journals from 13 scholarly publishers to show that the median half-life of journals is distributed between 24 and 60 months. In the case of engineering and technology subjects, the median half-life is greater than 36 months. We urge you to take his findings into consideration.

In the absence of any evidence to support 12 months as an appropriate embargo period, ASME recommends a 24 month embargo to ensure that we can fulfill our mission to the engineering community, as well as authors and scholars worldwide.

We appreciate the opportunity to provide you with our comments on the NIST Public Access Plan. We would welcome the opportunity to engage with NIST to discuss ways to determine appropriate and consistent implementation of embargo periods for specific scientific fields, and how to maximize the effectiveness of CHORUS to ensure the full benefits, reduced costs and decreased administrative burdens to NIST.

Thank you for the opportunity to present our views. Please contact Kathryn Holmes, Director, ASME Government Relations (holmesk@asme.org; 202.785.7390) if we can be of assistance.

Sincerely,

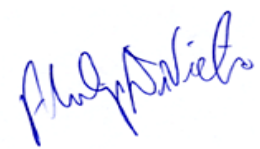

Philip DiVietro

Managing Director, ASME Publishing 
From:

Sent:

To:

Subject:

Attachments: public-access-bounces@nist.gov on behalf of John Tagler <jtagler@publishers.org> Thursday, August 20, 2015 5:08 PM

public-access

[Public-Access] AAP-PSP and STM response to NIST RFC on Public AAP STM comment on NIST public access plan.pdf; ATT00001.txt

Access Plan

Dear Ms. Sharpless,

I am submitting the attached letter on behalf of the Professional and Scholarly Publishing Division of the Association of American Publishers (AAP/PSP) and the International Association of Scientific, Technical, and Medical Publishers (STM), in response to the Request for Comments by the National Institute of Standards and Technology Plan for Providing Public Access to the Results of Federally Funded Research.

Thank you for your consideration.

Sincerely yours,

John Tagler

Vice President \& Executive Director

Professional \& Scholarly Publishing

Association of American Publishers, Inc.

71 Fifth Avenue

New York, NY 10003-3004

itagler@publishers.org

tel 212 255-1407

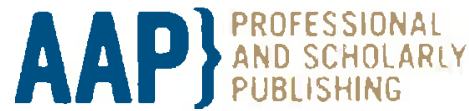

Privacy Notice:

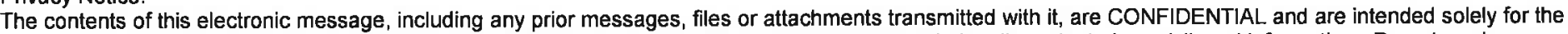

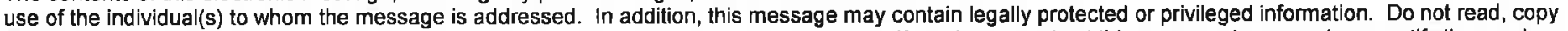

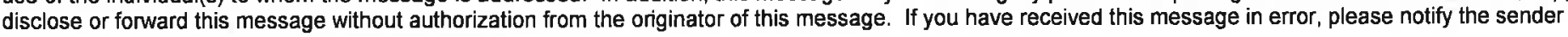
immediately and delete all copies from your system. 


\section{$110\} \begin{aligned} & \text { PROFESSIONAL } \\ & \text { AND SCHOLARLY } \\ & \text { PUBLISHING }\end{aligned}$}

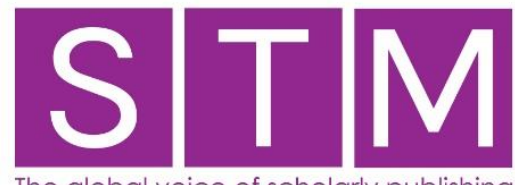

August 20, 2015

Katherine Sharpless

National Institute of Standards and Technology

100 Bureau Drive Stop 4701

Gaithersburg, MD 20899-4701

public-access@nist.gov

Re: Request for Public Comment: National Institute of Standards and Technology Plan for Providing Public Access to the Results of Federally Funded Research (Federal Register Doc. 2015-16508)

The Professional and Scholarly Publishing Division of the Association of American Publishers (AAP/PSP) and the International Association of Scientific, Technical, and Medical Publishers (STM) appreciate the opportunity to comment on the National Institute of Standards and Technology (NIST) Plan for Providing Public Access to the Results of Federally Funded Research (the Plan). AAP/PSP and STM are the major US and international trade associations for professional and scholarly publishers; like NIST, our 150+ members are guided by a commitment to advancing science, standards, and technology. Our members focus on creating and preserving the best scholarly communication, validated through peer review and disseminated worldwide to inspire new avenues of thought and advance discovery and innovation.

AAP/PSP and STM members include non-profit professional societies, commercial publishers, and university presses that create books, journals, computer software, databases, and electronic products in virtually all areas of human inquiry and activity. Collectively, they represent tens of thousands of publishing employees, editors and authors, and other professionals throughout the country who regularly contribute to the advancement of American science, medicine, learning, culture and innovation. They comprise the bulk of a $\$ 10$ billion publishing industry that contributes significantly to the U.S. economy and enhances the U.S. balance of trade.

Our members publish the vast majority of materials used in the U.S. by scholars and other professionals in the sciences and other areas of scholarship, and they are the worldwide disseminators, archivists and shapers of the scholarly record in both print and electronic form. They make significant intellectual contributions and investments that improve the quality, discoverability, and availability of peerreviewed articles and other publications. A major goal of our members' publishing activities is to help produce and provide access to high-quality peer-reviewed articles in a useful and user-friendly digital environment that enables researchers and other readers to discover, analyze, and link to the latest breakthroughs and developments in scholarly research. In particular, publishers of scientific and medical journals have, for more than 100 years, played an integral role in building and documenting the U.S. scientific research enterprise. Our members therefore are integral partners with the scholarly research community in the U.S. and with NIST as it seeks to promote research and innovation. 
AAP/PSP, STM, and our members have supported the principle that the public should have access to articles that report on federally funded research. AAP/PSP publicly supported the February 22, 2013 Executive Office of the President Office of Science and Technology Policy memo on "Increasing Access to the Results of Federally Funded Scientific Research" (the OSTP memo), and our members have been working for years on efforts to promote sustainable public access. These efforts include free or low-cost access to articles for target communities through Research4Life (in partnership with the United Nations), the Emergency Access Initiative (in partnership with the National Institutes of Health), patientINFORM (in partnership with health advocacy organizations), and patientACCESS, among others. They also include innovative business models like article rental and delayed access that allow for easy free or low-cost access in a sustainable system. Many of our members voluntarily provide free access to all articles that they publish after a delay that is appropriate for their journals' disciplines and practices. Our members, as well as AAP/PSP and STM on their behalf, have participated in and supported many public-private partnerships to deliver value to the public, and they are supporting the collaborative effort of CHORUS (the Clearinghouse for Open Research of the United States) to deliver public access in a way that minimizes costs for the public, agencies, researchers, and publishers alike.

In this spirit, we welcome the opportunity to comment on NIST's Public Access Plan. While we understand that the Plan has been carefully crafted and integrates comments from stakeholders throughout the process, there are many details that will still need to be worked out in the implementation stage and in future revisions to the plan. We appreciate NIST's commitment to having comments received "inform NIST as it revises its directives that implement the Plan."

The comments below focus first on the second question prompt, as our comments here inform those that follow. We then treat the other three prompts in the order provided. All comments and recommendations are meant to support NIST's successful implementation of the Plan in collaboration with all scholarly communication stakeholders, advancing public access while ensuring a sustainable publishing environment.

What are the biggest challenges to implementing a public access policy, and how can these challenges be addressed?

\section{Free access to articles has the potential to destabilize scholarly communication. NIST should maintain its commitment to proceed carefully, incrementally, and in close consultation with stakeholders to avoid unintended consequences}

We recognize that the implementation schedule takes an incremental approach and provides for regular reviews of the impact of the policy, which we believe is appropriate. We also appreciate the opportunity for all who are affected by the policy to comment, including through this Federal Register notice. In particular, we appreciate that the evaluation will consider "the relative values of long-term preservation and access and its associated costs and administrative burden."

Several sections of the Plan indicate that NIST will regularly consult with the scientific community, including publishers, and maintain ongoing discussions. Our associations and their members have engaged in consultations with a coalition of agencies at the National Academies (in May 2013) and the Forum on Open Science and look forward to continued engagement. We would welcome even more open communication as the Plan is implemented. 


\section{The burdens of implementation on researchers, research institutions, publishers, and NIST could be considerable and grow exponentially. Consider more extensive public-private partnerships to reduce burdens and support the sustainability of scholarly communication.}

The Plan's commitment that NIST "will establish a public access archive system" may have prevented NIST from considering options that could achieve its goals at lower cost and regulatory burden. We hope that NIST will consider leveraging existing resources where possible, as some other agencies have done in the development of their plan.

Although the Plan refers to PubMed Central as a public-private partnership, publishers have often felt that the implementation of PMC and the NIH Public Access Plan do not fully take their concerns into account. Some of these concerns include the diversion of traffic from publisher platforms, ${ }^{1}$ the difficulty in obtaining usage data on publisher content accessed through the National Library of Medicine (NLM), and the reformatting of published content for delivery through NLM. In addition, some of the tools available to PMC under the NIH Public Access Policy and mentioned in the NIST plan may not be available for articles reporting on research funded by NIST, which are not covered by current publisher agreements with NLM.

We would welcome the opportunity to work with NIST to address some of these issues, consistent with the Plan's commitment to exploring new approaches and partnerships and the "guiding principle" that NIST may make changes to accommodate new technologies and find solutions that scale with the volume of research and public access solutions. In particular, NIST should consider solutions offered by non-governmental organizations, particularly CHORUS (the Clearinghouse for Open Research of the United States), that could significantly reduce the regulatory burden of the Plan, lower costs for the government and grantees, and support the sustainability of scholarly communication.

The potential regulatory burden of the Plan should not be underestimated. According to the Association of American Universities, it takes " 23 steps and several emails for authors to submit manuscripts to PubMed Central" to comply with the National Institutes of Health's Public Access Policy, and others have suggested that the requirement is even more burdensome. A major study of the experience in the United Kingdom in implementing public access mandates quantifies the burden on UK researchers. The study found that the cost to research organizations of implementing mandates put in place by Research Councils UK and the Higher Education Funding Councils in 2013/14 was at least $£ 9.2 \mathrm{~m}$ and an amount of time equivalent to 110 fulltime staff members. The study also found that the compliance burden "falls disproportionally on smaller institutions." NIST should take steps to minimize any unnecessary costs and burdens in its implementation.

Distributed systems like CHORUS may also help with issues of integrating articles with appropriate databases and interoperability. Our members have found that integrating links to articles hosted by other publishers is possible in a single management system, and that services like CrossRef (which underlie some CHORUS services) facilitate such linking. CHORUS directly supports current policies and practices of researchers and publishers in providing access to articles and leverages resources already

\footnotetext{
${ }^{1}$ See Davis PM. 2013. Public accessibility of biomedical articles from PubMed Central reduces journal readership -retrospective cohort analysis. FASEB Journal 27 (7): 2536-2541 http://dx.doi.org/10.1096/fj.13-229922 and Davis PM. 2012. The Effect of Public Deposit of Scientific Articles on Readership. The Physiologist 55: 161-5 http://www.theaps.org/mm/Publications/Journals/Physiologist/2010-present/2012/October.pdf
} 
invested in by publishers. We understand that NIST is working on a pilot project with CHORUS and hope that this will lead to a true public-private partnership.

The Plan's staged approach to implementation should allow NIST to fully consider CHORUS and other possible options for providing access to support the research community in fully enabling public access. In contrast to the burdens reported for compliance with PMC, such solutions could enable automated compliance, reduce unnecessary federal investments, and allow researchers and their institutions to focus on research rather than administrative tasks.

We would also appreciate clarification of the requirement that authors submit copies of manuscripts to the NIST public access archive. In particular, this appears to conflict with the description of the utility NIST envisions from PMC, and would prevent researchers and NIST from taking advantage of existing infrastructure to minimize burdens for researchers, funded institutions, and publishers. Where possible, we recommend that NIST utilize and build on existing, independent, third-party services, including distributed systems like CHORUS and archive solutions like Portico and CLOCKSS.

\section{Differences in scholarly communication practices among disciplines means that NIST's public access policy will impact some fields more than others. NIST should provide additional opportunities to change the embargo for fields that have longer article lifecycles.}

We appreciate that the Plan includes an opportunity to petition for changing the embargo, and that the first mention of a 12-month embargo is modified by the right for NIST to change the embargo. We hope such an adjustment will be considered quickly, as the initial 12-month embargo for all disciplines is inconsistent with evidence and the need to sustain the quality, integrity, and availability of high-quality peer-reviewed articles reporting on scientific research.

Rather than setting a 12-month embargo for all articles, an evidence-based policy would recognize the differences among practices in various fields and set embargoes appropriately. According to a study by Dr. Phil Davis evaluating usage patterns in more than 2800 journals across 10 disciplines, ${ }^{2}$ half of the lifetime downloads for the articles published in a volume occur three years or more after publication for the majority of journals and this "half-life" varies considerably by discipline. This is important information, because usage is a key criterion for library subscription decisions. ${ }^{3}$ Surveys ${ }^{4}$ and direct communication with librarians further indicate that short embargoes could reduce the incentive to subscribe.

These results are consistent with the experiences of some of our members and with what is known about the use of articles by researchers. The American Psychological Association (APA) found that less than 16 percent of the usage of APA psychology journals occurs in the first year, and the American Mathematical Society (AMS) found that only 10 percent of the citations in the mathematics literature were to articles published in the previous three years combined. In addition, as reported by NSFsupported researchers at Indiana University, some papers in some fields can "remain dormant for years

\footnotetext{
2 Phil Davis, “Journal Usage Half-Life." www.publishers.org/usagestudy.

${ }^{3}$ For a survey of the research on cancellations related to usage data, see J. Williamson, P. Fernandez, and L. Dixon, "Factors in Science Journal Cancellation Projects: The Roles of Faculty Consultations and Data," Issues in Science and Technology Librarianship 78, Fall 2014. http://www.istl.org/14-fall/refereed4.html.

${ }^{4}$ See, e.g., http://blog.alpsp.org/2009/10/alpsp-survey-of-librarians-report.html
} 
and then suddenly explode with great impact upon the scientific community." ${ }^{5}$ This indicates that usage varies significantly between and among journals.

The importance of such evidence to the sustainability of journals and maintenance of subscriptions is supported by experience. To cite a few examples:

- The Genetics Society of America piloted a 3-month embargo for GENETICS and had "a high rate of subscription cancellations"; 6

- The American Journal of Pathology tried a 6-month embargo, and "subscription renewals declined precipitously"; ${ }^{7}$ and

- The Journal of Clinical Investigation found a too-short embargo unsustainable. After a 10-year experiment that saw the journal lose 40 percent of its institutional subscriptions, it had to reinstitute the subscription model to survive. ${ }^{8}$

Although each of these examples involves an embargo shorter than 12 months, each of them also involves a journal that publishes in the health sciences, which is the fastest-moving field and has the highest level of federal support. We would expect that journals in other fields would have similar issues with uniformly imposed 12 month embargoes.

Throughout the world, funders have implemented policies that recognize inherent differences among the practices of different disciplines, and we urge NIST to do the same. As one example, in the United Kingdom, policymakers have instituted as a starting point a 24-month embargo for articles in social science and humanities journals and 12 months for other disciplines. We recommend that NIST use the Davis study and other evidence to set differentiated embargoes by discipline, as suggested in the OSTP memo.

We also recommend that NIST consider expanding its criteria and approach to petitions for changing the embargo. We call your attention to language in the National Science Foundation's Public Access Plan, which calls for "factually and statistically based evidence that a change ... will more effectively promote the quality and sustainability of scholarly publications while meeting the objectives of public access." We also recommend that you allow any stakeholder, not just "NIST customers," to initiate such a petition.

The wrong policy carries the risk of undermining the quality and sustainability of scholarly communication and thereby reducing the availability to NIST-funded researchers of established, highquality journals in which to publish.

4. The costs for public access could quickly escalate, even as resources for research are constrained. NIST must ensure adequate resources are available to support allowable costs for access to publications and data.

Existing Department of Commerce practice allows grant proposals to include funds for communicating the results of the research, and the Plan notes that "costs for data preservation and access may be

\footnotetext{
${ }^{5}$ NSF News from the Field, "Like Sleeping Beauty, Some Research Lies Dormant for Decades, IU Study Finds," May 25, 2015. http://www.nsf.gov/news/news summ.jsp?cntn id=135258\&WT.mc id=USNSF_195\&WT.mc ev=click.

${ }^{6}$ http://www.whitehouse.gov/sites/default/files/microsites/ostp/scholarly-pubs-(\%23293)\%20gsa.pdf.

7 http://www.whitehouse.gov/sites/default/files/microsites/ostp/scholarly-pubs-(\%23259)\%20ASIP\%20response.pdf.

8 Reported in http://scholarlykitchen.sspnet.org/2009/02/26/end-of-free-access.
} 
included in grant proposals or project plan budgets for contracts." Although the Plan does not mention costs for publication explicitly, we hope that such costs for publishing and broadening access to articles, if applicable, continue to be allowed.

In addition, grantees frequently need supplemental funds for publication or for data access that were unforeseen at the time of the proposal, or for expenses that have been incurred after the grant period has ended. We encourage NIST to make sure that sufficient funds are available to cover all such expenses and also that "no-cost extensions" of grants are available without prejudice to enable the full communication of research findings whenever articles may be ready to be published.

\section{Public access policies could undermine intellectual property and copyright, and affect American competitiveness by shifting costs to the US that are currently borne worldwide. Such potential negative impacts should be regularly assessed and addressed.}

We appreciate the Plan's commitment that "NIST will...recognize .... intellectual property rights, avoiding significant negative impact on intellectual property rights, innovation, and U.S. competitiveness." Such a commitment needs to be followed with regular assessment and adjustment to the policy where there could be impact.

The Plan acknowledges that even when free access to content is provided, such content is still protected by copyright law. As the Plan is implemented, it must continue to allow authors, publishers, and other copyright holders to set licenses that are appropriate to the material covered, and avoid any overreach in terms of usage rights requirements. Appropriate licenses, together with appropriate embargoes, can help support the sustainability of scholarly publishing and ensure the quality and integrity of the scholarly record.

Inasmuch as the Plan is designed to promote U.S. economic competitiveness, care must also be taken to combat piracy by clearly communicating license terms and taking steps to prevent bulk downloads where the license does not allow such use.

What are the best practices (from academia, industry, and other stakeholder communities) in managing public access of data?

In addressing issues related to public access to data, flexibility is key. As with scholarly communication practices with respect to articles, different fields have unique research practices. The Plan implicitly recognizes this by focusing on Data Management Plans (DMPs), rather than creating universal requirements for all researchers.

In addition to publisher efforts to create and disseminate publications that report on and analyze the latest research, publishers have considerable experience and have made significant investment in digital technology, metadata standards, and tools to help users understand and work with data. Publishers support the discoverability and reuse of scholarly data and are actively working with researchers and standards organizations to develop tools and processes to ensure the availability and utility of such data. NIST should capitalize on existing standards and practices in different fields, and avoid creating new and conflicting requirements. 
As with sharing publications, there are considerable burdens to formatting data, tagging it with metadata, and otherwise preparing for the sharing of data. Publishers have found that collaborative private sector solutions can minimize costs and burdens for all involved, and we encourage NIST to leverage existing efforts. Publishers are working with repositories to better link to data, ensure quality citation, and develop metadata standards, and we look forward to continuing our partnerships with research communities in ensuring the quality and integrity of available data collections.

NIST could learn from initiatives already underway to standardize metadata and provide links between sources of research information. Issues related to expanding access, managing data, minimizing compliance costs, and other policy questions are already being worked through by various groups engaged with the issue. We encourage the continued evolution of programs that are working to improve data stewardship and public access to data. These include the Research Data Alliance (RDA), CrossRef, DataCite, Opportunities for Data Exchange (ODE), APARSEN, and the NISO/NFAIS Supplementary Journal Articles Material Project, among others. Such collaborative approaches provide the best way forward towards broad access to and preservation of digital data.

It is critical that NIST continue to distinguish between data and various types of presentation of data and preserve and respect intellectual property protection and copyright ownership as appropriate. The Data Publications Pyramid displayed here, ${ }^{9}$ derived from open science pioneer Jim Gray's e-science pyramid, provides a model for understanding how research data can be presented in a variety of ways with increasing levels of curation and analysis. NIST has already acknowledged the different levels of the pyramid by referring to "peer-reviewed publications and associated data" separately from

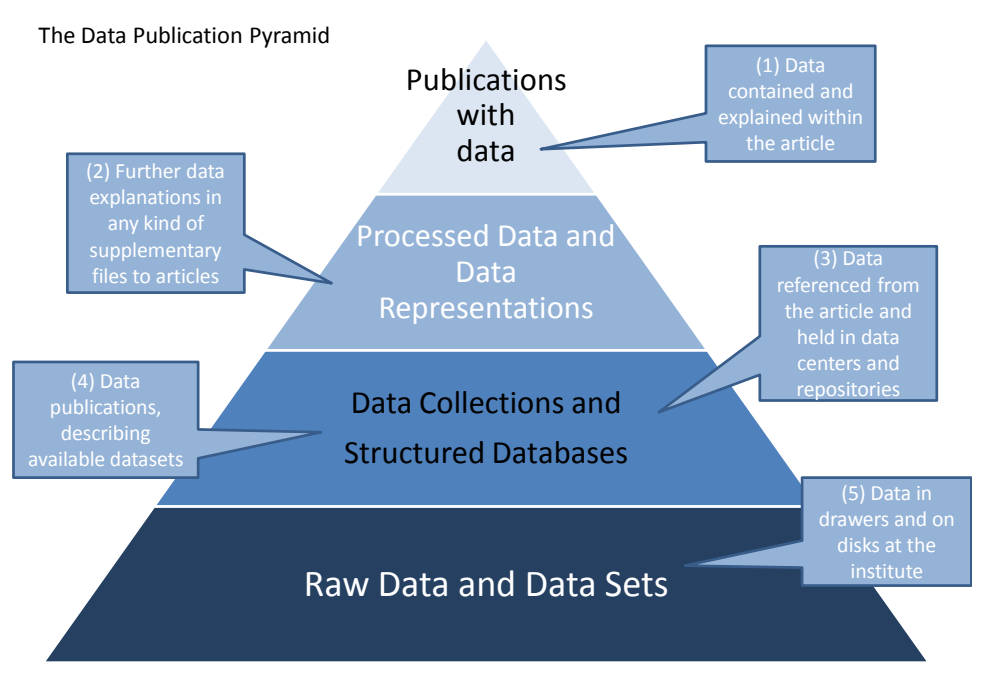
"NIST scientific data." As the Plan is implemented, NIST must continue to distinguish between information products at different levels of the pyramid and work with all stakeholders, including primary researchers, secondary researchers, publishers, libraries and data centers, to create clear rules and protocols for the sharing of data. A collaborative approach will ensure that the needs of each stakeholder group are addressed and that the progress of science is not impeded. In particular, the need to expand incentives for providing broad and timely access to new data must be balanced with the need to preserve incentives for researchers to interpret and analyze their results through curation and peer-reviewed publication.

Rather than imposing an inflexible mandate, NIST should focus on supporting and encouraging the development of cyber infrastructure, standards for the structure of data and metadata, navigation tools

\footnotetext{
${ }^{9}$ As appearing in the October 17, 2011 Report on Integration of Data and Publications, a report of Opportunities for Data Exchange which brings together stakeholders including researchers, publishers, libraries and data centers to support a more connected and integrated scholarly record. Full report available at http://www.alliancepermanentaccess.org/wpcontent/uploads/downloads/2011/11/ODE-ReportOnIntegrationOfDataAndPublications-1 1.pdf
} 
and applications to achieve discoverability and interoperability and ensuring appropriate and sustainable funding for innovation and long-term stewardship. These policies should be developed in collaboration with all key stakeholders involved in the presentation, analysis, deposit, storage, and preservation of data. NIST should promote a comprehensive framework for reliable digital data preservation, access, and interoperability through the promotion of standards and clear rules developed by the scholarly community. NIST could also support pilot projects, data curation programs, and interpretation initiatives for the relevant scholarly disciplines.

With regard to the top of the data pyramid and data associated with articles, NIST should encourage data to be deposited in accordance with the policies of the publication and standard citation practices, such as those being developed by the National Information Standards Organization (NISO) and others. In addition, NIST should recognize the need for different repositories for different communities. This is consistent with distributed approaches that have been successful throughout the research community and which could be successful for publications as well.

\section{What criteria could the NIST laboratories use in prioritizing the public release of datasets?}

As noted above, NIST should proceed carefully in imposing new burdens on researchers and in developing the capacity to accurately and consistently provide quality access to datasets. The best way to proceed would be to prioritize first those data that are already being made available and/or which already have proper formatting and tagging to ensure their integrity and utility. These data tend to be those towards the top of the pyramid. Publishers are already working with researchers to make such material more widely available and link them to articles that put the data in context and provide additional background on its collection.

NIST could also prioritize those data that are most useful to the public. Statistics on the use publicly available data can be obtained from existing data repositories or the use of material already available to NIST. Where the usage data is available to NIST through its own means, it would be helpful for NIST to share such data with content providers or the broader public. Publishers have helped develop the COUNTER system for accurate usage data collection on the usage of publications, and the sharing of COUNTER-compliant data by NIST would help improve the release and usage of datasets.

\section{How can NIST improve its plan to provide greater public access to NIST data?}

In addition to the recommendations above, the best way to improve the plan is through continued clear communication and engagement with scholarly community. The Plan consistently and repeatedly indicates that NIST will be actively engaged in consultation with all parts of the scholarly community, and we are encouraged that the Plan explicitly notes that implementation will take place over time. We hope that this will enable NIST to carefully assess the impact of its policies and adjust the plan as needed, in consultation with all stakeholders. We all urge NIST to consider both positive and negative effects on scholarly communication and the availability of diverse, high-quality peer-reviewed articles and research data in any analysis of the Plan. The high-quality peer reviewed articles that our members produce represent significant investments by publishing organizations to improve, disseminate, interpret, and steward those reports, and the ability to continue making those investments and ensuring the quality and integrity of the scholarly record depends on the sustainability of the publishing enterprise. 
Thank you for the opportunity to comment on the Plan. We look forward to future opportunities to provide input on and collaborate in ensuring access to high-quality peer-reviewed scholarly communication.

Sincerely,
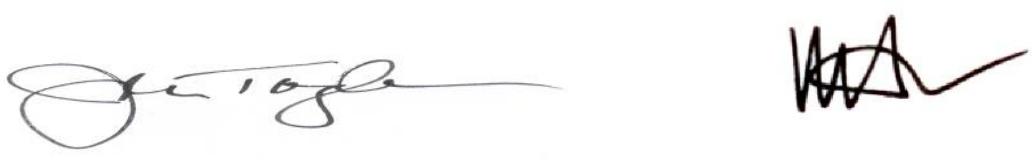

John Tagler

Vice President \& Executive Director

Professional \& Scholarly Publishing

Association of American Publishers, Inc.

71 Fifth Avenue, New York, NY 10003

455 Massachusetts Ave, Washington, DC 20001

jtagler@publishers.org

Phone: 212 255-1407
Michael Mabe

Chief Executive Officer

International Association of STM Publishers

Prins Willem Alexanderhof 5

The Hague, 2595 BE

The Netherlands

Mabe@stm-assoc.org

Phone: +441865339321 
Sharpless, Katherine E.

From:

Sent:

To:

Cc:

Subject:

Attachments:
Howard Ratner <hratner@chorusaccess.org>

Friday, August 21, 2015 10:18 AM

public-access

Sharpless, Katherine E.

National Institute of Standards and Technology Plan for Providing Public Access to the Results of Federally Funded Research

CHORUS NIST RFI 081715.pdf; ATT00001.txt

Dear Katherine,

I am submitting the attached letter on behalf of CHORUS (Clearinghouse for the Open Research of the United States). We appreciate this opportunity to respond to the Request for Comments on the NIST Public Access Plan.

Like NIST, CHORUS is committed to delivering a public-access solution that avoids duplication of effort, minimizes administrative costs, and maximizes compliance. We look forward to continuing our collaboration with NIST in a pilot project to achieve these important objectives.

Thank you for your consideration.

All the best.

-- Howard 


\section{CHORUS}

August 21, 2015

Katherine Sharpless

National Institute of Standards and Technology (NIST)

100 Bureau Drive Stop 4701

Gaithersburg, MD 20899-4701

\section{RE: National Institute of Standards and Technology Plan for Providing Public Access to the Results of Federally Funded Research}

CHORUS (Clearinghouse for the Open Research of the United States), a US 501(c)(3) non-profit organization, appreciates this opportunity to respond to the Request for Comments on the NIST Public Access Plan.

By leveraging existing infrastructure, tools, and services that support access, sharing, discoverability, reporting, and preservation, CHORUS helps research funders effectively and sustainably facilitate public access. CHORUS members and signatories collectively produce the vast majority of published peerreviewed journal articles. We currently track an estimated 9,000 journals that our members collectively publish and monitor over 135,000 articles reporting on funded research for public access and long-term availability, more than 30,000 of which are already freely accessible to the public. CHORUS reports this data via 24 agency dashboards, which also provide access to each article we monitor. CHORUS has made excellent progress working with funding agencies to support their approach to providing public access. The US Department of Energy and Smithsonian Institution have signed participation agreements with CHORUS, and the NSF, NASA, NOAA have all directly mentioned CHORUS in their plans. We are in active negotiations with and, in some cases, are pursuing pilot projects with eight other U.S. federal agencies.

Like NIST, CHORUS is committed to delivering a public-access solution that avoids duplication of effort, minimizes administrative costs, and maximizes compliance. We look forward to continuing our collaboration with NIST in a pilot project to achieve these important objectives.

\section{What are the biggest challenges to implementing a public access policy, and how can these challenges be addressed?}

As NIST develops and implements its public-access policy, it will be critical to ensure that its policy achieves the goal of expanding public access without imposing undue administrative burden and costs on taxpayers and researchers. We applaud NIST's recognition of this challenge and ongoing commitment to engage in "full and open consultation and cooperation with stakeholders," "create flexible approaches" to

accommodate the range of research and diversity of stakeholders, "plan for change," and adopt "evolvable solutions" that respond to new needs and digital technologies, and develop processes for the "continual update and evaluation" of policies to ensure effectiveness and relevance while also weighing the "costs and administrative burden." The CHORUS-NIST collaboration is guided by these principles and represents a unique and important opportunity to leverage innovative technologies to better serve the public need. We greatly appreciate the openness of NIST leadership to partnering for the public benefit. 
NIST has also indicated that it will require its funded investigators submit an electronic version of final peer-reviewed journal manuscripts to PubMed Central (PMC) upon acceptance for publication. We are hopeful that NIST can help to actively support robust public-private partnership and to engender a more open collaboration around public access policy and policy implementation than is currently the case between PMC and the publishing community. One way would be to work with NIH to embrace open international standards - particularly DOIs, CrossRef's FundRef, ORCID, and COUNTER usage statistics - to improve interoperability between its PMC infrastructure and other platforms on which versions of the same articles appear. In our unique role as a non-profit organization set up to provide agencies and publishers with a sustainable solution to delivering public access to published articles reporting on federally funded research, CHORUS is well-placed to help facilitate and support this richer engagement among NIST, NIH, and the full range of other stakeholders, including libraries, universities, scholarly societies, and research organizations.

\section{What are the best practices (from academia, industry, and other stakeholder communities) in managing public access of data? How can NIST improve its plan to provide greater public access to NIST data?}

CHORUS supports NIST's efforts to encourage researchers to make their research data freely available, with easily discoverable reuse restrictions. CHORUS engages with stakeholders to develop tools and services to support researchers with data management, and to help funding bodies with compliance tracking. We would welcome the opportunity to collaborate with NIST and other stakeholders - national and international, and across all disciplines and sectors - to leverage existing systems, experience, and expertise, in order to ensure minimal duplication of effort and maximum efficiency.

In particular, the need to develop - and continue to develop - data standards is critical. We strongly encourage NIST to actively partner with the organizations already overseeing the development and management of these standards and to recommend and deploy existing tools such as DOIs, FundRef, and ORCID to grant recipients for their data management. CHORUS would be very interested in working with the NIST, publishers, data-archive managers, and other stakeholders on developing a data-validation system, as well as mechanisms to connect articles and related datasets, for example, via developing publishers' systems to enable authors to submit their data to an appropriate archive and simultaneously link this to an article. I work with the CrossRef-DataCite Pilot, SHARE, and the RDA-WDS Publishing Data Services Working Group, and CHORUS is in discussions with the RMap

Project, Dataverse, Figshare, and Dryad.

Sincerely,

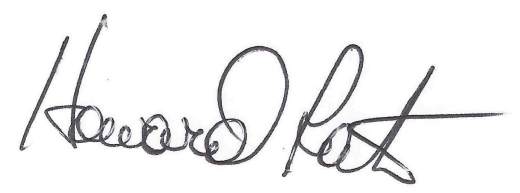

Howard Ratner

Executive Director, CHORUS / CHOR, Inc.

h.ratner@chorusaccess.org

917-251-9235 


\section{Sharpless, Katherine E.}

From:

Sent:

To:

Subject:

Attachments: public-access-bounces@nist.gov on behalf of David Wojick <davidwojick@insidepublicaccess.com>

Wednesday, August 12, 2015 3:13 PM

public-access

[Public-Access] Comments on NIST's Public Access plan, as requested

NIST Public Access comments from Inside Public Access by Wojick.pdf; NIST Public Access comments from Inside Public Access by Wojick.doc; ATT00001.txt

Hello Katherine Sharpless,

Attached are my initial comments on NIST's Public Access plan, in response to your July 7, 2015 Federal Register notice, in two formats -- PDF and Doc. I will be pleased to answer any questions you may have regarding these comments.

Thank you for this opportunity.

David

David E. Wojick, Ph.D.

http://insidepublicaccess.com/ 
To: Katherine Sharpless,

NIST

By email to public-access@nist.gov

August 12, 2015

\section{Inside Public Access comments on the NIST Plan for Providing Public Access to the Results of Federally Funded Research (NIST Public Access Plan).}

NIST officially requested comments on its Public Access plan in the July 7, 2015 Federal Register. Inside Public Access is a newsletter and consulting service with a deep interest in the US Public Access program. We are especially interested in making Public Access work as well as possible, while minimizing the burden on the research community.

We are therefore pleased to make the following comments:

The legal background here is that the Paperwork Reduction Act (PRA), which NIST specifically cites, requires that all federal agencies obtain a clearance before they collect information from the public. Requiring authors to submit copies of their published articles is certainly an information collection under PRA.

This request for comment is presumably a step in the clearance process, or at least feeds into it. NIST may even change its Public Access Policy in response. In any case it will then submit an Information Collection Request (ICR) to OIRA. Central to the ICR is a so-called burden estimate, which typically focuses on the hours of public labor required to understand and comply with the collection requirements.

The point is that this is the time for interested parties to raise whatever issues they have with NIST's proposed Public Access Policy. The primary issue areas are the need for the articles, how to maximize their value and how to minimize the burden of providing them. CHORUS obviously plays into the burden issue, so NIST needs to justify not using CHORUS.

Statutory authority for the collection may also be an issue because there is no clear authority given by Congress for the US Public Access program. It was created by an Executive Branch memo. NIST needs to address this issue, as their Authority section provides no actual statutory authority.

Whether the government has a right to demand and publish these copyrighted articles may also be an issue, in view of the potential for damaging the copyright holders. This brings the copyright issue to the fore and NIST needs to address this issue.

Just to elaborate, I have been talking to the Energy Department's Office of Science about this issue. They claim that their right to collect and publish journal articles is based on the 
acquisition regulation 2 CFR 200.315(b).

http://www.gpo.gov/fdsys/pkg/CFR-2014-title2-vol1/xml/CFR-2014-title2-vol1-sec200-

$\underline{315 . x m l}$

Here is the text of that regulation:

"(b) The non-Federal entity may copyright any work that is subject to copyright and was developed, or for which ownership was acquired, under a Federal award. The Federal awarding agency reserves a royalty-free, nonexclusive and irrevocable right to reproduce, publish, or otherwise use the work for Federal purposes, and to authorize others to do so.”

As I read this the journal article (the work) has to have been written (developed) under the award. The award contracts all have specific end dates. Journal articles are often written after the contract end date, because one does not write up the results until the research is over. Such articles are not developed under the award.

As I read this the government has no right to these post-contract articles, but NIST is going to collect and publish them under the US Public Access program. I suppose one can argue that the research was part of the development, but then what is being copyrighted is the ideas not the text and that is incorrect. The copyright only begins with the writing.

The basic point is that the NIST Public Access program is a separate information collection. Submitting published articles to a funding agency is clearly an information collection, because the agency gets the information. But so is one researcher sharing data with another, when that activity is mandated by agency rule, as it is under the Public Access program. So the data sharing requirements will also have to be cleared through OIRA.

Every proposal must include what is called a data management plan or DMP. The DMP says how the researcher will make available and share their data, which then becomes a contract commitment if they are awarded a grant.

It is true that preparing a DMP is part of the burden of a proposal, but there is also the potentially much larger burden of preparing and sharing data. It can be very laborious to prepare data for others to use. It can require a lot of refining, formatting, documentation and explanation.

The point is that NIST should be estimating how much sharing will go on and what the burden is. It appears that this is not being done. More broadly, all of the agency Public Access programs that use the data management plan requirement should be clearing the burden of data sharing with OIRA.

How to estimate (and minimize) the burden of mandated data sharing is a research problem, one that NIST should take seriously. There are really just two questions to be answered in estimating burden. First, how often will required sharing happen? Second, what will the average burden likely be? 
Note that the DMP data sharing requirement does not end when the research contract ends, far from it. This is also true of the requirement to submit published articles, but data requests can come long after publication. Article usage data suggests that data requests may well come many years after publication. So the estimate of how many mandated data sharings will occur needs to take into account this potential longevity.

As to the average burden per request, here the problem is the extreme vagueness of the requirement. What is emerging as the standard requirement language is something to the effect of "whatever the community normally requires to validate the research" which NIST specifically cites.

As regulatory language this is hopelessly vague, so hopefully standard practices will develop. It does seem to be leading in some cases to discipline specific agency research programs developing their own specific data sharing rules.

The specialization of data sharing rules may well be happening at other agencies as well, or develop in the future as the Public Access program matures. It may make sense scientifically but it also makes burden estimation more complex. It may also make the goal of minimizing burden more difficult to pursue, given the multiplicity of discipline specific requirements.

A related concern is that this vague DMP requirement can be taken to mean that the data to be shared is whatever the requestor wants. The danger here is that imposing burden via endless requests can be used as a political weapon.

We already see this in some cases with Freedom of Information Act (FOIA) requests. But while FOIA puts the burden on the agency, Public Access data requests put the burden on the public, namely the researcher. Data sharing rules may be needed to limit this sort of abuse.

Note too that the fact that a researcher deposits their data in a repository does not mean that their burden ends. People requesting data from the repository may well then ask the researchers for explanations, more documentation, or even more data. The vagueness of the DMP requirements may contribute to this.

It seems likely that the burden of Public Access data sharing mandates may be large, even very large. The agencies and OIRA need to take this potential burden seriously and take steps to minimize it. The first step is to do proper burden estimating. NIST can take the lead in this important research.

\author{
Respectfully submitted by \\ David Wojick, Ph.D. \\ http://insidepublicaccess.com \\ davidwojick@insidepublicaccess
}


Sharpless, Katherine E.

From:

Sent:

To:

Subject: barbara sachau <bsachau@gmail.com>

Tuesday, July 07, 2015 3:16 PM

Sharpless, Katherine E.; PUBLC.ACCESS@NIST.GOV; vicepresident; americanvoices@mail.house.gov; info; media@cagw.org; scoop Re: nih funding research at rutgers on whether worms can swim or not - says its for agnig - what do you think

\section{PUBLIC COMMENT ON FEDERAL REGISTER}

THE PRESIDENT SAID HE WANTED THIS 5 YEARS AGO OR MORE. TO DATE, NIST HAS FAILED TO ACT PROMPTLY. WHY IS THAT. THE TAXPAYERS SHOULD HAVE HAD THIS INFORMATION ALL ALONG. WHY IS IT TAKING SO LONG AN D CONTINUING TO TAKE SO LONG. THIS COMMENT IS FOR THE PUBLIC RECORD. PLESE RECEIPT. JEAN PUBLI JEANPUBLIC1@,GMAIL.COM

On Tue, Jul 7,2015 at 9:46 AM, barbara sachau <bsachau@gmail.com> wrote:

[Federal Register Volume 80, Number 129 (Tuesday, July 7, 2015)]

[Notices]

[Pages 38668-38669]

From the Federal Register Online via the Government Publishing Office [www.gpo.gov]

[ER Doc No: 2015-16508]

\section{DEPARTMENT OF COMMERCE}

National Institute of Standards and Technology

[Docket Number: 150414364-5364-01]

National Institute of Standards and Technology Plan for Providing

Public Access to the Results of Federally Funded Research

AGENCY: National Institute of Standards and Technology, Department of

Commerce.

ACTION: Notice; request for public comment.

SUMMARY: The National Institute of Standards and Technology (NIST) seeks comments on the NIST Plan for Providing Public Access to the Results of Federally Funded Research (NIST Public Access Plan). NIST is taking steps to make its scientific data and publications more readily available and accessible by the public, as directed in several recent White House memoranda. The NIST Public Access Plan applies to the results of research funded wholly or in part by NIST, presented in peer-reviewed scholarly publications and as research data. This document outlines NIST's plan for implementing new responsibilities and procedures to manage the public access of scientific data and publications. The NIST Public Access Plan was reviewed by the Office of Science and Technology Policy and the Office of Management and Budget; 
they approved it on December 4, 2014. Comments received on the NIST Public Access Plan will inform NIST as it revises its directives that implement the Plan.

DATES: Comments must be received by 11:59 p.m. Eastern Time on August 21,2015 to be considered.

[ [ Page 38669] ]

ADDRESSES: Written comments may be submitted by any of the following methods:

Email: public-access@nist.gov.

Fax: 301-975-8620, Attn: Katherine Sharpless.

Mail: Katherine Sharpless, NIST, 100 Bureau Drive Stop 4701, Gaithersburg, MD 20899-4701.

Please be aware that all comments will be publicly posted online at http://www.nist.gov/data. Comments containing references, studies, research, and other empirical data that are not widely published should include copies of the referenced materials. All comments will be made public; therefore personal, proprietary, or confidential information should not be included.

FOR FURTHER INFORMATION CONTACT: Katherine Sharpless by phone at 301975-3121 or by email at katherine.sharpless@nist.gov.

Please direct media inquiries to Jennifer Huergo, NIST Office of Public Affairs, by phone at 301-975-6343 or by email at

jennifer.huergo@nist.gov.

SUPPLEMENTARY INEORMATION: The National Institute of Standards and Technology (NIST) is one of our Nation's oldest Federal laboratories (for more information, visit www.nist.gov). As a bureau in the Department of Commerce, the NIST mission is to promote U.S. innovation and industrial competitiveness by advancing measurement science, standards, and technology in ways that enhance economic security and improve our quality of life. From early electrical measurement research to today's quantum information science, NIST has long been, and continues to be, a center for high-impact research meeting the needs of academia, industry, and government. The NIST laboratories conduct world-class research, often in close collaboration with industry, which advances the nation's technology infrastructure and helps U.S. companies continually improve products and services.

NIST publishes this notice to seek comments on the NIST Plan for Providing Public Access to the Results of Federally Funded Research (NIST Public Access Plan), posted at www.nist.gov/data. The NIST Public Access Plan documents NIST's plan to implement new responsibilities and procedures to manage the public access of scientific data and publications. Comments received on the NIST Public Access Plan will inform NIST as it revises its directives that implement the Plan.

NIST is taking steps to make its scientific data and publications more readily available and accessible by the public, as directed in several recent White House memoranda, Office of Management and Budget Memoranda M-10-06, Open Government Directive, and M-13-13, Open Data Policy-Managing Information as an Asset; and the Eebruary 22, 2013, Office of Science and Technology Policy Memorandum, Increasing Access to the Results of Federally Funded Scientific Research.

The NIST Public Access Plan applies to the results of research funded wholly or in part by NIST, presented in peer-reviewed scholarly publications and as research data. Research data means the recorded factual material commonly accepted in the scientific community as necessary to validate research findings, but not any of the following: preliminary analyses, $\backslash 1 \backslash$ drafts of scientific papers, plans for future 
research, peer reviews, or communications with colleagues. This

"recorded' material excludes physical objects (e.g., laboratory

samples). Research data does not include: Trade secrets, commercial

information, materials necessary to be held confidential by a

researcher until they are published, or similar information which is

protected under law; and personnel and medical information and similar

information the disclosure of which would constitute a clearly

unwarranted invasion of personal privacy, such as information that

could be used to identify a particular person in a research study. \2\

$\backslash 1 \backslash$ For purposes of NIST's Public Access Plan, NIST considers

the contents of laboratory notebooks to be preliminary analyses.

$12 \backslash$ For purposes of this notice, NIST is adopting the definition

of 'research data' ' provided in 2 CER 200.315(e) (3). http://www.gpo.gov/fdsys/pkg/CER2014-title2-voll/pdf/CER-2014-title2-voll-sec200-315.pdf.

Putting new plans in place to manage public access to NIST data and publications stands to significantly benefit the public and NIST by ensuring that the integrity of NIST data and publications is maintained throughout their life cycles, and by increasing the visibility of NIST measurements, standards, technology, and research activities.

Stakeholder consultation is a critical step in the development of NIST's plan for managing public access to research results.

In May 2013, NIST co-sponsored two public comment meetings at the National Academy of sciences on providing public access to federally supported R\&D data and publications. \3\ The stakeholder input gathered at these public meetings and information from ongoing dialogue with other Federal agencies were considered in the development of the NIST Public Access Plan. NIST invites respondents to comment on the following questions that pertain to the implementation of its public access policy:

13\ Public Comment Meeting Concerning Public Access to Federally Supported R\&D Publications Workshop, held May 14-15, 2013, and Public Comment Meeting Concerning Public Access to Federally Supported R\&D Data Workshop, held May 16-17, 2013, at the National Academy of Sciences.

What are the best practices (from academia, industry, and other stakeholder communities) in managing public access of data?

What are the biggest challenges to implementing a public access policy, and how can these challenges be addressed?

What criteria could the NIST laboratories use in

prioritizing the public release of datasets?

How can NIST improve its plan to provide greater public access to NIST data?

All comments must be received in accordance with the DATES section of the notice above.

Richard Cavanagh,

Acting Associate Director for Laboratory Programs.

[FR Doc. 2015-16508 Eiled 7-6-15; 8:45 am]

BILLING CODE 3510-13-P 


\section{Sharpless, Katherine E.}

From:

Sent:

To:

Subject:

Attachments: public-access-bounces@nist.gov on behalf of Tein, Andrew - Hoboken <antein@wiley.com>

Friday, August 21, 2015 2:45 PM

public-access

[Public-Access] Comment on NIST Public Access Plan

Wiley NIST Submission 082115.pdf; ATT00001.txt

Hi Katherine

Hope that you have been well. Please find attached comments from John Wiley and Sons (Wiley) on the NIST Public Access Plan. Please let me know if you have any questions. We look forward to working with NIST to advance public access to publications and data.

Thanks very much,

Andrew

Andrew Tein

Vice President

Global Government Affairs

Wiley

111 River St

Hoboken, NJ 07030

USA

www.wiley.com

T $\quad+12017487751$

M +12012734129

E-mail antein@wiley.com

WILEY 


\section{WILEY}

August 21, 2015

Katherine Sharpless

National Institute of Standards and Technology (NIST)

100 Bureau Drive Stop 4701

Gaithersburg, MD 20899-4701

\section{RE: National Institute of Standards and Technology Plan for Providing Public Access to the Results of Federally Funded Research}

I am writing on behalf of John Wiley \& Sons, the leading American publisher of scientific research. Wiley was founded in 1807 and has 2,600 employees across the country. We publish over 1,600 journals across all major scholarly disciplines and partner with over 1,200 non-profit professional and scholarly societies which represent nearly 15 million researches around the world.

Wiley is committed to working with funders, researchers and other stakeholders to expand access to high-quality, peer-reviewed articles. Together we can develop sustainable models that expand access and strengthen the system of scholarly communication, recognizing the investments publishers make in managing peer-review, publishing and disseminating articles, and preserving research for the future.

We appreciate the opportunity to provide comments on the NIST Plan for Providing Public Access to the Results of Federally Funded Research in response to the Federal Register notice on July 7, 2015.

What are the best practices (from academia, industry, and other stakeholder communities) in managing public access of data?

Wiley is committed to working with its authors and agencies to enable greater access to digital data. In June 2015 Wiley announced a groundbreaking partnership with the data repository organization Figshare to integrate data sharing within existing journal workflows and article publication. The new data sharing service is being piloted with a number of titles and rolled out over the following few months along with new data citation and data sharing policies. This will ensure that more data is accessible, sharable and reproducible under a creative commons license from articles on Wiley Online Library without any cost to the author or readers.

We look forward to working with NIST as it seeks to promote data sharing over the coming years. In particular, we appreciate that NIST will be "taking into account the efforts of public- and private-sector entities" as it outlines repository options for scientific data in digital formats. As these efforts advance we encourage NIST to consult with stakeholders, align with ongoing activities in the research community and leverage existing infrastructure instead of creating duplicative federal repositories.

What are the biggest challenges to implementing a public access policy, and how can these challenges be addressed?

111 River Street, Hoboken, NJ 07030-5774, U.S.

$\mathrm{T}+12017486000$

$F+12017486088$

www.wiley.com 


\section{Embargoes and Petitions}

One of the key challenges in developing a sustainable public access policy will be to ensure that it provides sufficient time for publishers to recoup their significant investments in the peer-review and publishing processes. Indeed, the long-term success of "green" public access policies depends on a vibrant subscription base to support private sector investments.

To this end, we are concerned that the initial 12-month embargo chosen by NIST for all journal articles covered by the policy could be too short for many publishers and societies to recoup their investments in the peer-review and publishing processes and continue to produce the highest-quality scientific research literature. Disciplines vary significantly in their publishing cultures and usage patterns, and what may be appropriate for certain rapidly-moving fields of research may be unsustainable for others. A variable approach to embargoes is essential to accommodate this diversity and ensure sustainability. Such an approach has been taken by other funders around the world including policymakers in the UK, who set an initial 12-month embargo for STEM disciplines and a 24-month embargo for the arts, humanities and social sciences.

We appreciate that NIST has, in accordance with the OSTP memorandum, included a petitions mechanism to adjust this embargo period. This is a critical safeguard to ensure the NIST plan does not harm the system of scholarly communication and can respond flexibly to accommodate the diversity of research and stakeholders. However, we are concerned that the criteria for adjusting the embargo period - "providing evidence that the current embargo period does not provide a public benefit and is inconsistent with the objectives articulated in the OSTP memo" - diverges from the primary purpose of such a period, which is to preserve the sustainability and quality of scholarly publications. As a potential alternative approach, we would highlight the criteria outlined in the National Science Foundation public access plan, which calls for petitions to present evidence that a change in the embargo period "will more effectively promote the quality and sustainability of scholarly publications while meeting the objectives of public access." In addition, we would recommend that NIST allow any stakeholder to make such a petition, not just "NIST's customers."

Such a measured, reflective, and stakeholder-driven approach will be essential to develop a sustainable public access policy and adjust as needed to address challenges in the course of implementation.

Implementation and Repositories

NIST has indicated that it will use the NIH's PubMed Central (PMC) repository to implement its public access plan. As PMC can act in direct competition with other stakeholders and unnecessarily duplicate functions already being performed by other actors, we would encourage NIST to explore other more cost-effective options for implementing its public access plan that leverage journals' existing infrastructure. Wiley and a coalition of other publishers and societies, who collectively publish the vast majority of articles reporting on federally-funded research, are committed to helping agencies implement their public access plans through the Clearinghouse for the Open Research of the United States (CHORUS). Distributed systems like CHORUS can save taxpayer dollars, avoid unnecessary duplication and reduce compliance burdens. We look forward to future discussions on how CHORUS can be leveraged to support implementation of agency public access plans.

If NIST does use PMC, we would encourage it to consider ways in which the system could be improved upon: 
- If PMC is used, rely on relevant industry standards rather than creating proprietary identifiers and link to authoritative article versions if the version of record is not available within PMC. The current approach of using PMC IDs instead of industry-standard DOls encourages traffic to remain within PMC.

- If PMC is used, clearly display copyright information where relevant and provide usage statistics for manuscripts deposited in PMC by publishers on behalf of authors. The National Library of Medicine (NLM) does not communicate effectively to stakeholders and partners critical information, including usage of accepted manuscripts posted on PMC and clear guidance on article copyrights, both ownership and re-use terms.

- If PMC is used, do not expand services in ways that dilute its mission and effectiveness, such as the creation of derivative products and services without consultation with publishers and other stakeholders and establishing overseas mirror repositories when other access and repository options already exist.

- If PMC is used, consider developing additional services to improve public access to its databases, such as API access to Medline/PubMed. Enabling programmatic access to database content will increase dissemination of publically-funded material and will encourage the development of innovative products and services based upon NLM data.

\section{Intellectual Property Protection}

Strong intellectual property protections underpin the information economy and support the ability of rightsholders to continue to publish high-quality, peer-reviewed scientific literature. As such, we appreciate NIST's commitment to "recognize.....intellectual property rights, avoiding significant negative impact on intellectual property rights, innovation, and U.S. competitiveness." In particular we appreciate NIST's clear acknowledgment that articles made freely accessible are still protected by copyright laws. To ensure the sustainability of scholarly publishing and prevent the undermining of copyright, it will be important to continue to allow rightsholders to set appropriate license terms, ensure such license terms are clearly communicated, and take steps to prevent bulk downloads and infringement in cases where licenses do not allow such use.

\section{How can NIST improve its plan to provide greater public access to NIST data?}

Wiley looks forward to partnering with NIST as it implements its initial public access plan. Experience from around the world suggests that the adoption of any such plan is never a simple endeavor, and that both expected and unexpected challenges will emerge over the course of this process. To respond nimbly to these challenges and make improvements and adjustments to its plan, it will be important that NIST continue to adopt a flexible approach to public access and engage openly and regularly with the scholarly community.

Thank you for your consideration of these comments regarding the NIST public access plan. We look forward to collaborating with NIST as it refines and implements its public access plan and remain committed to strengthening the system of scholarly communication in support of researchers and funders in the United States and around the world. 
Sincerely,

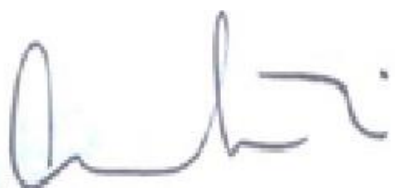

\section{Andrew A Tein}

Vice President, Global Government Affairs

Wiley

Office: +1 2017487751

e-mail: antein@wiley.com 
Sharpless, Katherine E.

From:

public-access-bounces@nist.gov on behalf of Huftalen, Adam (REI-WAS)

<Adam.Huftalen@relx.com>

Sent:

Friday, August 21, 2015 8:42 AM

To:

Subject:

public-access

Attachments:

[Public-Access] RELX Group Comments on NIST Public Access Plan

RELX Group NIST Public Access Plan Comments FINAL.pdf; ATT00001.txt

Hello - please find RELX Group's comment letter attached, and please feel free to contact me should you have any questions.

\section{Adam Huftalen}

Senior Manager, Federal Government Affairs

RELX Group

1150 18th St. NW

Suite 600

Washington, D.C. 20036

202.857.4644 (Direct)

202.320.3816 (Mobile)

adam.huftalen@relx.com

Elsevier | LexisNexis Legal \& Professional | LexisNexis Risk Solutions | Reed Business Information | Reed Exhibitions

The information in this transmittal (including attachments, if any) is privileged and confidential and is intended only for the recipient(s) listed above. Any review, use, disclosure, distribution or copying of this transmittal is prohibited except by or on behalf of the intended recipient. If you have received this transmittal in error, please notify me immediately by reply email and destroy all copies of the transmittal. Thank you. 


\section{QRELX Group}

August 21, 2015

Dr. Willie E. May

Director

National Institute of Standards and Technology

100 Bureau Drive Stop 4701,

Gaithersburg, MD

20899-4701

Re: Comments on the National Institute of Standards and Technology's Public Access Plan

Dear Dr May:

RELX Group (formerly Reed Elsevier) welcomes the opportunity to comment on the National Institute of Standards and Technology's (NIST) Public Access Plan. RELX Group is one of the world's largest providers of professional information solutions, with more than 13,000 U.S. employees and more than 28,000 employees worldwide.

Elsevier, a RELX Group company, is a world-leading provider of scientific, technical and medical information products and services. We serve 30 million scientists, students and health and information professionals worldwide. We help advance science and health by providing world-class information and innovative tools that help customers make critical decisions, enhance productivity, and improve outcomes

Elsevier publishes more than 2,000 journals, including The Lancet and Cell, and a growing portfolio of open access titles. We also publish close to 20,000 book titles, including major reference works such as Gray's Anatomy and titles from Mosby and Saunders. Elsevier's online solutions include ScienceDirect, Scopus, Reaxys, ClinicalKey and Mosby's Nursing Suite, which enhance the productivity of science and health professionals by providing quick and efficient access to published research, and the SciVal suite and MEDai's Pinpoint Review, which help research and health care institutions deliver better outcomes more cost-effectively.

Elsevier is an integral partner to the scholarly research community in the United States. Our US Elsevier workforce includes about 3,000 people spread across 15 offices in 10 states. We publish about 350,000 journal articles each year, many of which are authored by US researchers and of which approximately 35,000 acknowledge support from the US government. We are the single largest publisher of journal articles that report on research funded by the Department of Energy. In addition, we publish over 250 journals in partnership with US scholarly societies, such as The Combustion Institute, Hydrogen Energy Publications and The International Energy Initiative. Elsevier publishes $18 \%$ of articles which report on research funded by the U.S. Department of Health \& Human Services (HHS) each year. 
RELX Group and Elsevier support the principle that the public should be able to access publicly-funded research and we demonstrate this support through a broad array of sustainable public access options in our 2000+ journals, and through our universal access initiatives. We provide free or very low-cost access to hundreds of medical journals via patient information services such as Patient Inform and patientACCESS. In addition, through a program called Research4Life, we provide free or low-cost access to Elsevier journals and books to more than 6,000 institutions in more than 100 developing countries.

Elsevier also participates in the NIH's Emergency Access Initiative. This important initiative provides temporary free access to full text articles from major biomedicine titles to healthcare professionals, librarians, and the public affected by emergencies and disasters such as the ebola outbreak and the aftermath of the Nepal earthquake.

We also welcome the collaborative public-private partnership with federal agencies in the Clearinghouse for Open Research of the United States (CHORUS), a multi-publisher portal to provide access to journal articles reporting on government-funded research.

The principle of ensuring access to published research by means of public access is one that we entirely support. What is at issue is not the principle of public access, but the form that it should take in order to make it work in a sustainable fashion.

RELX Group is pleased to provide the following comments on the NIST Public Access Plan.

\section{Sustainable Public Access Policies with Variable Embargoes Are Essential to Scientific Research and High-Quality Scholarly Communication}

We are very concerned that NIST's public access plan includes a "one-size-fits-all" twelve-month postpublication embargo for journal articles in all disciplines. Embargo periods are necessary because the subscription business model is relied on to support the making available of versions of articles outside of a subscription. Selling subscriptions enables publishers to recoup a return on investment in our journals and to continue to reinvest to support the scholarly communications system. When versions of articles are made available too early, this reduces the incentive for our customers to subscribe to journals and therefore makes it difficult for us to secure a return on our investment. Embargo periods therefore need to be set according to the usage patterns we see in journals, specifically not too early so that it is worth a customer continuing to subscribe.

Setting embargos at the optimum level requires careful consideration and the aim is to strike a balance between making a version of an article publically available but not too early so as to undermine the continuing viability of a journal. Studies have shown that when embargo periods are set too low, the incentive to buy a journal decreases. Studies have similarly shown that usage patterns, which help determine the time at which it becomes viable for a version of an article to become publically available, vary between disciplines, but also within different disciplines. This was a key conclusion of a comprehensive usage study of over 2800 journals across 10 disciplines, conducted by Dr. Philip M. Davis. ${ }^{1}$ Looking across all

\footnotetext{
${ }^{1}$ Journal Usage Half-Life By Philip M. Davis, Ph.D. Phil Davis Consulting; http://www.publishers.org/_attachments/docs/journalusagehalflife.pdf
} 
disciplines, Davis found that the majority of journals had a usage half-life of 3 years or more, and that only 3 percent of journals had half-lives of less than 12 months. Usage half-life is defined as the time taken for articles to reach half of their total number of downloads.

\section{KEY FINDINGS FROM JOURNAL USAGE HALF-LIFE BY DR. PHILIP M. DAVIS}

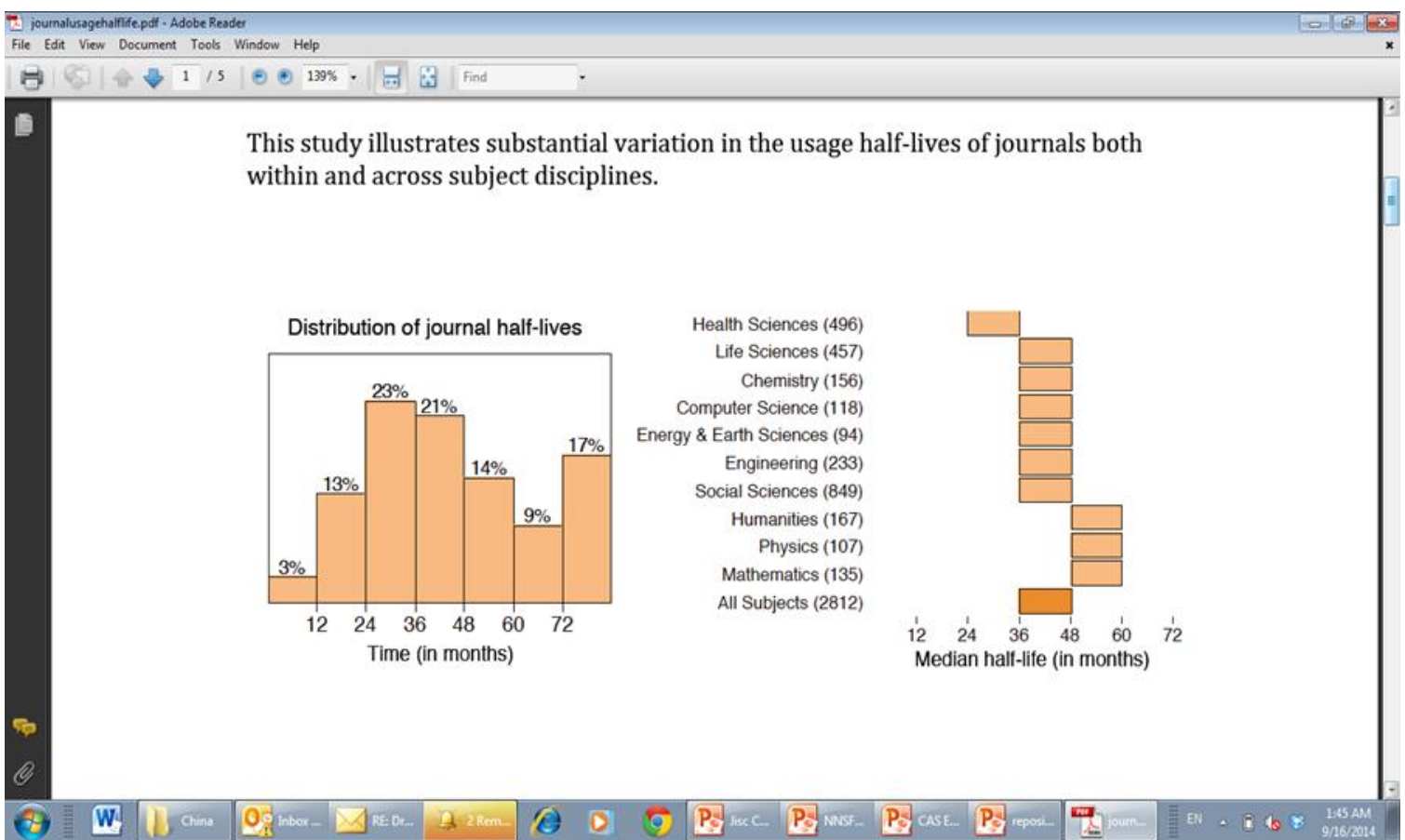

These results are consistent with previous studies on journal usage in different disciplines. For example, in their 2012 submission to the White House Office of Science and Technology Policy, the American Psychological Association (APA) noted that less than 16\% of the usage of APA psychology journals occurs in the first year. Similarly, an analysis in 2009 by the American Mathematical Society found that only $10 \%$ of the citations in the mathematics literature were to articles published in the previous three years combined. Further, a study of journal publishing in the humanities and social sciences concludes that, given the comparatively long life of articles in those fields, the imposition of embargo periods that are being adopted for biomedical journals could threaten the sustainability of humanities and social science journals. ${ }^{2}$

These studies clearly demonstrate that a 12 month embargo period would be unsustainable in some disciplines and that variation in embargo periods are needed to take account of differences within and between disciplines. With this evidence in mind, we urge NIST to reconsider its approach and allow for variable embargo periods on a discipline-specific basis, using the evidence provided alongside other

\footnotetext{
2 "The uture of Scholarly Journals Publishing Among Social Science and Humanities Associations," Report on a study funded by a Planning Grant from the Andrew W. Mellon Foundation (February 2009), available at: http://www.nhalliance.org/bm doc/hssreport.pdf
} 
relevant data. This will ensure the continuation of robust and dynamic, high-quality scientific and scholarly communication system.

Additionally, we are encouraged that NIST has included a process to allow publishers to petition for an exception to the established embargo where they can provide supporting evidence demonstrating that the established embargo is not viable. This is consistent with the February 22, 2013 OSTP memo on Increasing Access to the Results of Federal Funded Scientific Research that directs agencies to provide a mechanism for stakeholders to petition for changing an established embargo.

\section{The NIST Plan Will Incur Unnecessary Costs by Duplicating Efforts Provided by the Private- sector, including the Clearing House for the Open Research of the United States (CHORUS).}

RELX Group and Elsevier welcome opportunities to enhance delivery of public access through collaboration and strongly urge NIST to consider partnership approaches to public access which avoid duplication of effort and minimize both costs and administration for researchers and their institutions. One of the significant collaboration opportunities in facilitating public access is via the CHORUS service (http://www.chorusaccess.org/), which leverages existing infrastructure, tools, and services that support sharing, access, discoverability, reporting, and preservation.

CHORUS also reduces the compliance burden on authors, and in turn increases compliance with public access goals.

We are concerned that NIST has not given consideration to how this new approach presents opportunities for cost-savings within federal agency budgets and for institutions receiving federal agency research support. A planned collaboration with CHORUS would achieve this aim, and also the OSTP objective of leveraging existing infrastructure and fostering public-private partnerships with scientific journals relevant to the agency's research. One example of successful collaboration to date includes the partnership between the U.S. Department of Energy (DoE) and CHORUS, which is currently leveraging open standards, distributed networks, and established infrastructure to enable agency indexing of articles and advance access to publicly available research articles that acknowledge DOE funding (http://www.chorusaccess.org/us-department-of-energy-and-chorus-sign-participationagreement-to-advance-public-access/). We would urge NIST, either independently or through its partnership with NIH and PMC, to explore the opportunities that the CHORUS service can provide for facilitating public access.

\section{The NIST Plan Should Promote Public-Private Partnerships}

We encourage NIST to look for additional opportunities to leverage public-private partnerships. We believe collaboration between our organizations to achieve shared goals could be significantly improved in the following ways:

i. $\quad$ Elsevier urges NIST to share COUNTER-compliant distributed usage statistics for manuscripts which report on NIST funded research in PMC so that publishers can continue to report on impact and usage to authors and to their institutions that subscribe to these publications and pay their publication costs. 
ii. It is also critical that NIH cease reformatting and enhancing manuscripts to make them appear more like, and substitute for, the final version-of-record of articles. This duplicative process only adds cost to PMC and its partnering agencies like NIST.

iii. Finally, it is essential that PMC ensure readers are presented with the best version of the article available, which means that entitled users are transparently linked to the final published version of articles reporting on NIST funded research.

\section{NIST's Approach to a Data Repository Solution Should Allow for Optimal Data Use}

RELX Group and Elsevier support the principle that raw research data should be freely available, and have both a research data policy and a number of tools and services to support researchers who wish to share and access data. We therefore support NIST's vision for data sharing; however, we feel strongly that researchers should be free to deposit their data in repositories best suited for their research and where they feel their data can be most discoverable and accessible, best preserved, and analyzed using discipline-specific tools as often provided by discipline-specific repositories.

Specifying where data should be deposited could limit the opportunity for flexible approaches to data submission, access, understanding, and use.

We would also welcome reassurance from NIST that federal research data repositories will be looking to collaborate with publishers and other stakeholders to help make data discoverable and interpretable in the context of associated publications. Some examples of Elsevier's collaborations with data repositories to date can be found here.

We appreciate the opportunity to provide you with our comments on the NIST Public Access Plan. We would welcome the opportunity to engage with NIST to discuss ways to determine appropriate and consistent implementation of administrative intervals for specific scientific fields, and how to maximize the effectiveness of CHORUS to ensure the full benefits, reduced costs and decreased administrative burdens to NIST.

Sincerely,

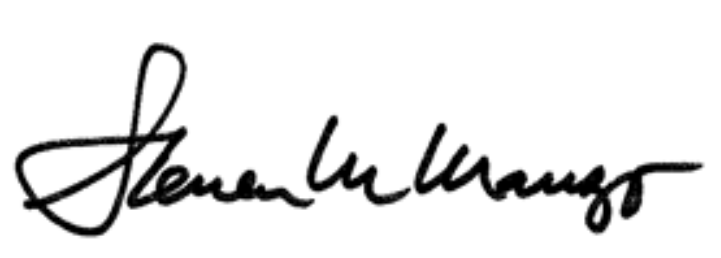

Steven M. Manzo

Vice President

Global Government Affairs Americas

RELX Group 
Appendix D. NIST Data Taxonomy and Actions/Consequences for Data Categories

\section{PURPOSE}

The purpose of this taxonomy is to define a collection of terms and concepts that describe classes and categories scientific data arising from unclassified research and programs funded wholly or in part by NIST ${ }^{1}$, as well as policy requirements, actions, and consequences that might apply to those categories as a result of requirements expressed in the Office of Science and Technology Policy (OSTP) Open Data Memorandum, OMB Memorandum M-13-13, and Executive Order 13642. (See NIST Policy P 105.01.) In the context of these requirements, research data is defined as "the recorded factual material commonly accepted in the scientific community as necessary to validate research findings, but not any of the following: preliminary analyses, drafts of scientific papers, plans for future research, peer reviews, or communications with colleagues."

Although the categories in the NIST data taxonomy are arranged in a pyramid, they are not strictly hierarchical. Categories range from working data to standard reference data (SRD) (see Figure 1). The goal of this document is to achieve a shared understanding of the data management space at NIST, not to make policy choices or to define requirements or recommend procedures. This vocabulary is intended to enable discussions among NIST management and technical staff to support NIST's data management Policy and Order.

\footnotetext{
${ }^{1}$ A non-NIST organization that publishes scholarly and technical material, including data, through activities funded wholly or in part by NIST through a grant, cooperative agreement, contract, or other agreement, must manage public access to published scholarly and technical material, including data, as agreed to by NIST and that organization in the terms and conditions of the grant, cooperative agreement, contract, or other agreement between NIST and the non-NIST organization.

${ }^{2}$ For purposes of this policy, NIST is adopting the definition of "research data" provided in 2 C.F.R. $\$ 200.315$

(e)(3). http://www.gpo.gov/fdsys/pkg/CFR-2014-title2-vol1/pdf/CFR-2014-title2-vol1-sec200-315.pdf
} 


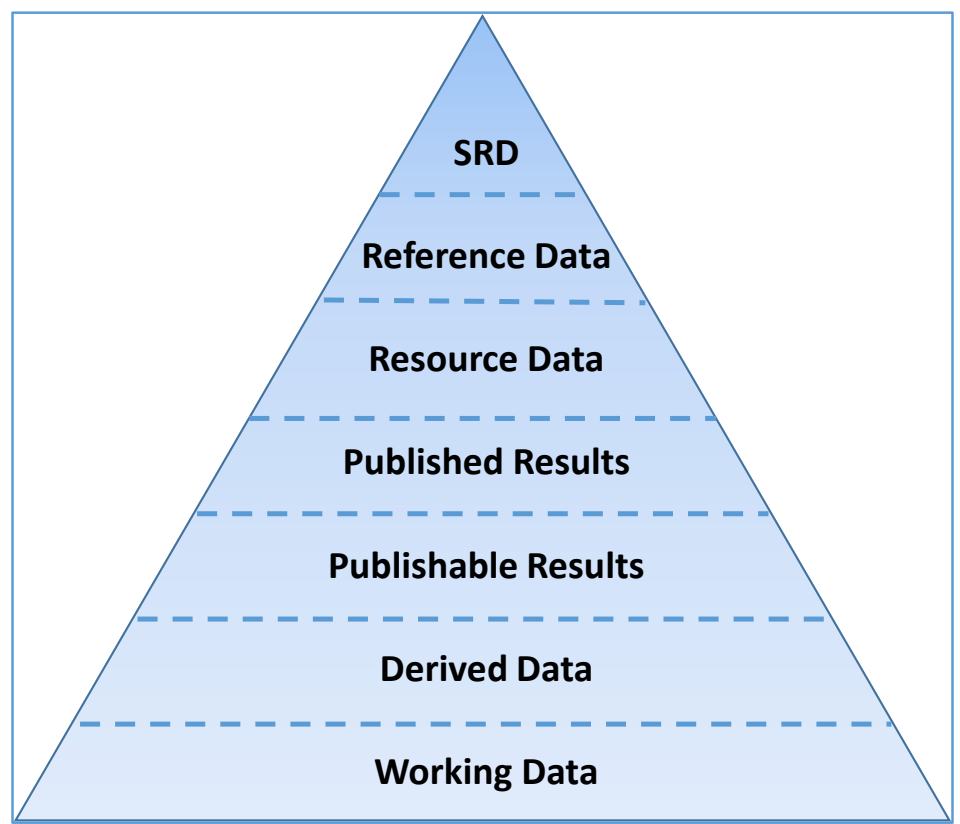

Figure 1. Data pyramid describing the categories of NIST data, ranging from "Working Data" to "Standard Reference Data (SRD)"

\section{DATA CATEGORIES}

The main categories envisioned for NIST data have been arranged in the form of a "data pyramid," (Figure 1) recognizing that in general the volume of data decreases as you move from the bottom of the pyramid toward the top. This is an oversimplification, and several competing dimensions for characterizing and distinguishing data classes have been combined into this one view for reasons of simplicity and compactness. However, this simplified diagram (Figure 1) provides a useful breakdown of data classes for the narrow context of discussing data management plans and NIST data curation and dissemination policies.

Several classes of data are described in the pyramid, with the following definitions:

\section{Working Data}

The digital equivalent of entering data in a laboratory notebook. Working data may be raw observational data that is acquired directly from an instrument or a measurement system, or digital values acquired or generated during experiments or simulations. In some cases the researcher responsible for generating the working data may determine that this data has immediate value and is worth preserving, or the researcher may expect that the data will have value after it has been manipulated or further evaluated, and the data has the potential to develop into a publication or will be used to draw conclusions. In other cases working data may be recognized as not appropriate for broader use in its present form. It may have value to the data 
producers and their collaborators, but it should be recognized that the data could be easily misinterpreted by people not closely involved in its production because some metadata and important facts about its status or acquisition are not readily available beyond the immediate research team (e.g., adequate metadata for re-purposing is not attached to the data itself, or expending resources to codify needed metadata is not justified, etc.).

\section{Derived Data}

Underpins the conclusions provided in a publication or report. Derived data comes from working data that has been manipulated, analyzed, processed, or evaluated in some way. The data must have passed some minimal (perhaps ad hoc) evaluation and be considered by the responsible researcher (typically the data producer) to be ready for the next steps in the workflow or project/product development effort.

\section{Publishable Results}

All final or summary results that comply with relevant NIST policies (e.g., SI units, uncertainty statements), that have been reviewed internally and approved by an appropriate NIST authority, and that could be published either in a scientific publication or as a standalone data product.

\section{Published Results}

Results that are publishable and that are contained in a document that has been reviewed and approved for publication by the necessary NIST organizational authorities, submitted to its intended publisher, and made public.

\section{Resource Data}

Data used to underpin, support, or defend decisions, actions, or positions of NIST.

\section{Reference Data $(\mathbf{R D})^{3}$}

Data similar in many characteristics to SRD, sharing features of organization, documentation, and evaluation with SRD. The primary difference between RD and SRD is that reference data is not distributed under the authority of the Standard Reference Data Act

\section{Standard Reference Data}

Data that has been collected from documented sources, organized, critically evaluated using a procedure that is documented, and distributed, as described in the Standard Reference Data Act. The Standard Reference Data Act defines standard reference data as "quantitative information, related to a measureable physical or chemical property of a substance or system of substances of known composition and structure, which is critically evaluated as to its reliability under [the

\footnotetext{
${ }^{3}$ It should be noted that the definitions for standard reference data and reference data in this document are similar but not identical to those in the International Vocabulary of Metrology (VIM). There are two key differences: the definition of standard reference data is adopted from the SRD Act, and both definitions are broader than those in the VIM since the VIM only refers to measured data. The VIM defines reference data as being "related to a property of a phenomenon, body, or substance, or to a system of components of known composition or structure, obtained from an identified source, critically evaluated, and verified for accuracy." The scope of reference data as used in this document expands beyond physical and chemical properties.
} 
provisions of the Standard Reference Data Act]." ${ }^{\prime 4}$ Standard Reference Databases are copyrightable, and NIST may secure copyright in them.

\section{ACTION/CONSEQUENCE LEVELS}

While the section on Data Categories is intended to define a variety of classes or grades of data that exist at NIST, this section defines corresponding requirements or consequences that should be considered when formulating data policy. As explained earlier, the purpose of this taxonomy document is not to impose these consequences or required actions on the categories, but merely to provide a vocabulary that simplifies discussion of assigning such requirements to various categories. Expressions of NIST data policy (e.g., NIST Directives, Guidance Memoranda, OU policies, etc.) should contain statements that map these consequence levels onto specific categories. Incorporating this taxonomy document as a reference into policy documents that delineate such mappings will simplify those statements of policy and reduce their ambiguity.

Figure 2. Mapping preservation consequence levels onto the NIST data categories.

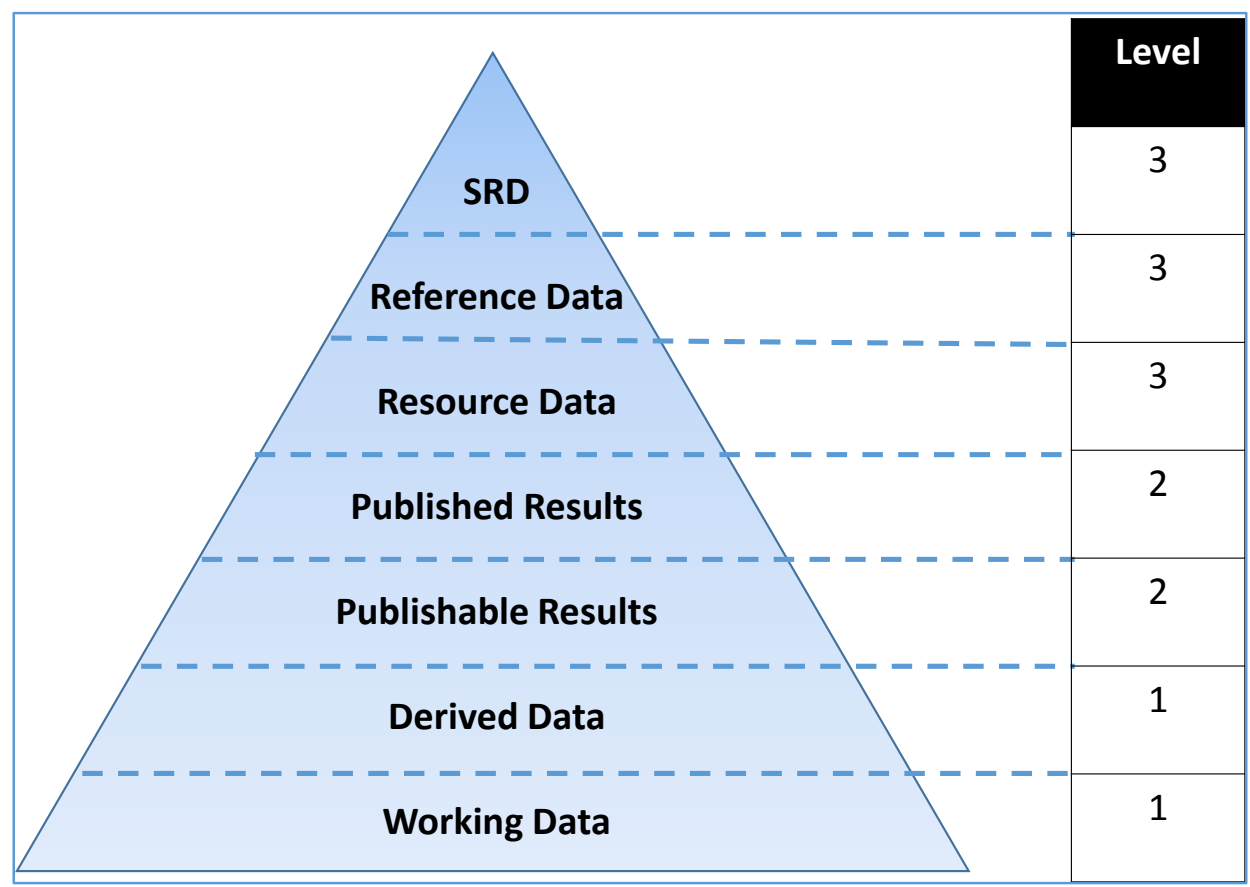

\section{Preservation Consequence Levels Defined}

Consistent with NIST Administrative Manual Subchapter 2.06 Records Management, ${ }^{5}$ the NIST Records Retention Schedule ${ }^{6}$ for Scientific and Technological Records, ${ }^{7}$ and the General

\footnotetext{
${ }^{4} 15$ U.S.C. § 290a, Standard Reference Data Act, http://0-www.gpo.gov.librus.hccs.edu/fdsys/pkg/USCODE-1995title15/pdf/USCODE-1995-title15-chap7A.pdf.

5 http://inet.nist.gov/mando/directives/206.cfm

${ }^{6}$ http://inet.nist.gov/mando/nist-records-schedule.cfm

7 http://inet.nist.gov/mando/services/upload/Items-25-32-Scientific-and-Technological-Records.pdf
} 
Records Schedule ${ }^{8}$ for Input Records, Output Records, and Electronic Copies, ${ }^{9}$ the following preservation consequence levels correspond to the Data Categories in the data pyramid (See Figure 2):

1. No preservation requirements,

2. Individual user responsible for preservation of data,

3. Data must be backed up using a tested/automated process (i.e., proof that restoration is possible). ${ }^{10}$

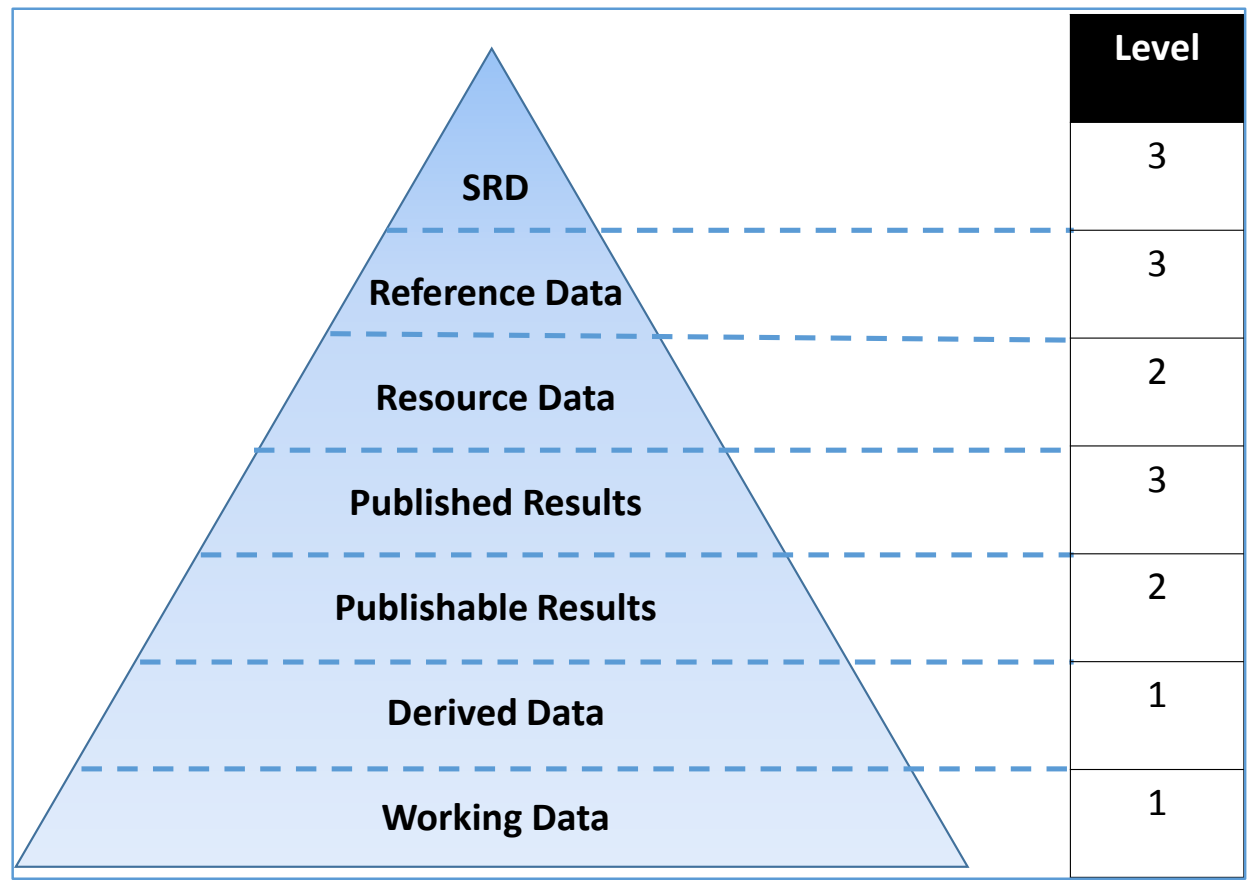

Figure 3. Mapping review consequence levels onto the NIST data categories.

\section{Review Consequence Levels Defined}

The following review consequence levels correspond to the Data Categories in the data pyramid (See Figure 3.):

1. No additional review requirements,

2. Technical aspects of the data must be reviewed and approved within the OU following OU policies.

3. Review by other appropriate NIST authorities (e.g., WERB, ODI) is required.

\footnotetext{
${ }^{8}$ http://www.archives.gov/records-mgmt/grs.html

${ }^{9}$ http://www.archives.gov/records-mgmt/grs/grs04-3.pdf

10 The data are backed up periodically, but the backup frequency is left unspecified and commercial backup technologies such as Tivoli Storage Manager are employed, OR the data are backed up at the level of OISM Central File Services Tier 2, OR the data are backed up at the level of OISM Central File Services Tier 1.
} 


\section{Discoverability Consequence Levels Defined}

The following discoverability consequence levels correspond to the Data Categories in the data pyramid (See Figure 4.):

1. No discoverability requirements,

2. Metadata values must be entered into the NIST Enterprise Data Inventory (i.e., the NISTXM $^{11}$ metadata) and a Persistent Identifier (PID) minted for the dataset,

3. Metadata values in the NIST Enterprise Data Inventory are made publicly accessible.

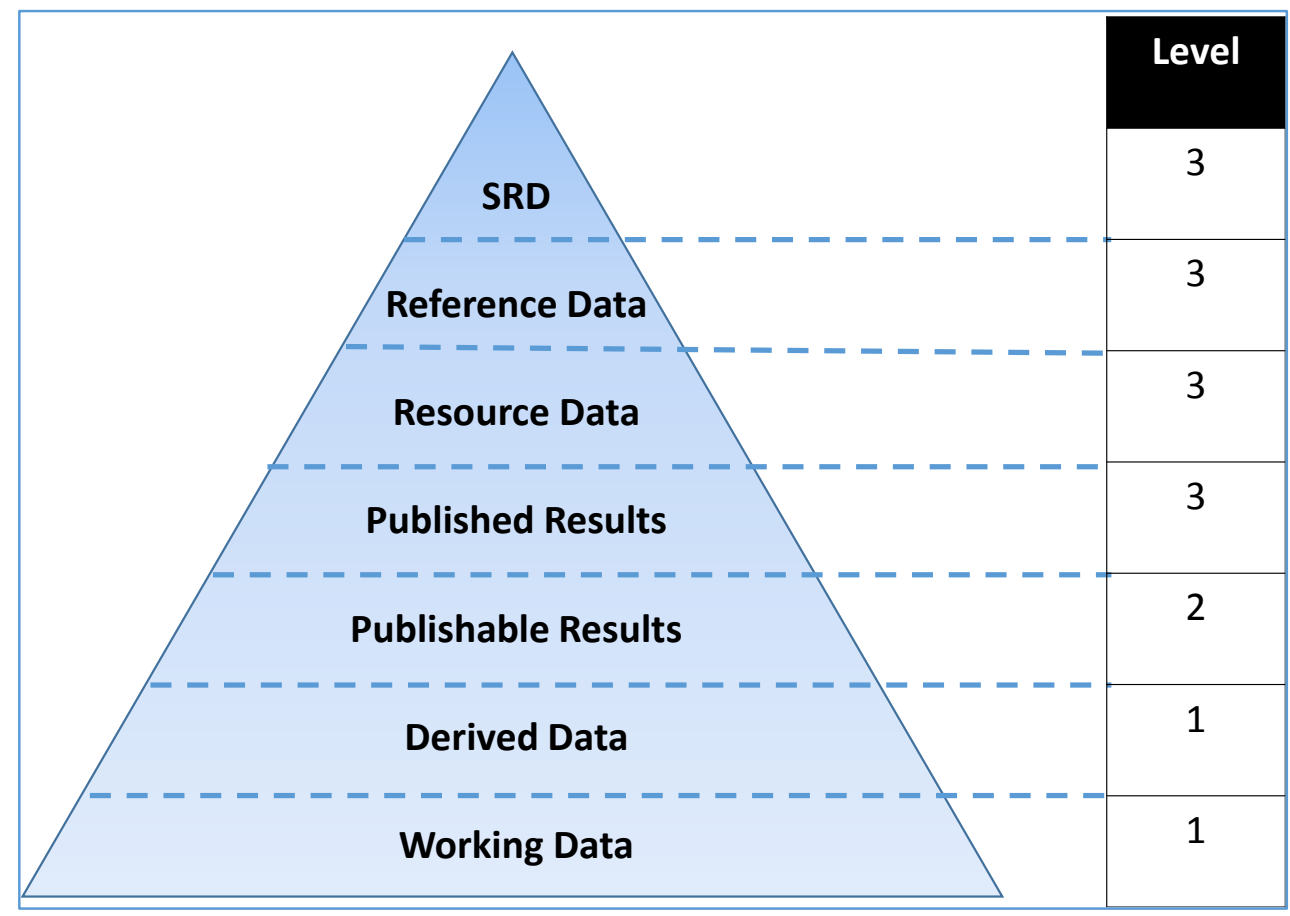

Figure 4. Mapping discoverability consequence levels onto the NIST data categories.

In addition to the guidance above, additional considerations should also be applied by each OU and Office to prioritize the availability of datasets based on factors including stakeholder need, the reasonableness of effort required to make the data available, and other relevant factors.

\section{RELEVANCE OF THE NIST IT SYSTEM SECURITY PLANS}

There is a very close relationship between NIST data and the information technology (IT) systems used to store, utilize, and exchange that data. Further, extensive NIST policy governing

\footnotetext{
${ }^{11}$ The NIST Extensible Metadata Schema is a definition of the minimum metadata values to be associated with NIST datasets. Formerly known as the "NIST Common Core," the NISTXM is a very minor extension of the OMBrequired Common Core metadata fields.
} 
IT systems has already been defined, and NIST has numerous special publications and Federal Information Processing Standards (FIPS) for the benefit of the nation, pursuant to the Federal Information Security Management Act (FISMA) of 2002 and other legislation relative to information technology.

Federal law ${ }^{12}$ defines the three components of a widely accepted model for discussing information security, including both IT security and information assurance:

a. Integrity: guarding against improper information modification or destruction, including ensuring information nonrepudiation and authenticity;

b. Confidentiality: preserving authorized restrictions on access and disclosure, including means for protecting personal privacy and proprietary information; and

c. Availability: ensuring timely and reliable access to and use of information.

This security model applies to information, information systems, and related resources (including user information such as research results), and therefore is much broader than just NIST data. However, these concepts are relevant to data generated by federally funded research.

FIPS Publication $199^{13}$ defines three levels of potential impact on organizations and individuals should there be a breach of security (i.e., in this context a loss of confidentiality, integrity, or availability of the data). The potential impact can be LOW, MODERATE, or HIGH if the loss of confidentiality, integrity, or availability could be expected to have a limited adverse effect, a serious adverse effect, or a severe/catastrophic effect on organizational operations, organizational assets, or individuals. These impact levels are clarified and amplified in FIPS 199. When federally funded research is intended for publication, its INTEGRITY and CONFIDENTIALITY impacts are LOW since the unauthorized modification or disclosure of the data would have a limited adverse effect on NIST operations, assets, and individuals. However, if the federally funded research contains business or personally identifiable information, proprietary information, or other sensitive information prior to publication, CONFIDENTIALITY is deemed MODERATE and therefore requires more stringent security controls. Business or personally identifiable information, proprietary information, or other sensitive information must never be published or otherwise made public. The data categorization and security controls must be documented within the respective NIST OU system security plan.

Preservation of records may be accomplished through various means. (NIST staff can see 'How do I backup my data' for more information.)

\footnotetext{
12 See 44 U.S.C $\$ 3542$ - Definitions.

${ }^{13}$ FIPS 199, "Standards for Security Categorization of Federal Information and Information Systems," NIST, February 2004, available at http://csrc.nist.gov/publications/fips/fips199/FIPS-PUB-199-final.pdf.
} 